\title{
ESTUDIOS
}

\section{La Literatura y la Revista Literaria en Hispanoamérica}

(Continuación de los numeros 51 y 52)

\section{NICARAGUA}

LA Torre de MARfil. León-Managua. Revista literaria. Mensual. 1909-;

1919-.

Director: S. Argüello.

Véase: Carter, 180.

Letras. Managua. I, 1, julio 1913-.

Directores: J. R. Avilés, R. Sáenz Morales.

Véase: Carter, 178-179.

Nicaragúa Informativa. Managua. I, 1, enero 1917-1922.

Directores: S. Herrera Flores, L. Lacayo S., H. Robleto, M. Sancho.

Véase: Carter, 179.

Los Domingos. Managua. Revista literaria semanal e ilustrada. 19181920.

Director: S. Ruiz Morales.

Véase: Carter, 178.

Darío. León. 1920.

Revista Femenina Ilustrada. Managua. 1921-1931.

Directora: J. Toledo de Aguerri.

Yéase: Carter, 180 : 
LA Noticia Ilustrada. Managua. Suplemento literario del diario la Noticia. 1926-1927.

Director: J. R. Avilés.

Véase: Carter, 179-180.

Criterio. Granada. 1929.

Véase: Carter, 177.

Mujer NiCaragüense. Managua. Revista quincenal ilustrada. 1931 1934.

Directora: J. Toledo de Aguerri.

Véase: Carter, 179.

ÓPERA BUFA. Managua. 1936-1938.

Director: J. Zavala Urtecho.

Véase: Carter, 180.

Éxıro. Managua. Revista gráfica y literaria.

Bimensual. 1936-1939. (PAU).

Director: J. León Cojina U.

RuTA. Jinotega. Revista literaria trimestral. 1937-; 1944-1945.

Director: A. Alegría.

SoldeAmÉrICA. Managua. Revista de cultura literaria. 1938. (PAU).

Directores: G. Castellón, G. G. Espinosa.

PARA Todos. Managua. Economía, historia, política y literatura.

Semanal. I, 1, 22 septiembre 1938-. (PAU).

Director: F. Torres Fuentes.

Centro. Managua. Revista literaria y científica. 1939-1940. (TU; UT).

Director: J. Román.

Véase: Carter, 177.

Mentalidad. Managua. Revista que fomenta la cultura mental de Nicaragua.

Mensual. I, 1, octubre 1939-. (PAU).

Director: E. Sequeira.

ANHelos. Masaya. Periódico literario. 1940-1941.

Directores: E. Mejía Sánchez, D. M. Robles Zamora.

Véase: Carter, 177.

¡YA! Managua. Magazine popular nicaragüense. 1941.

Director: A. Ordóñez Argüello.

Véase: Carter, 181. 
Los Lunes. Managua. Suplemento literario ilustrado de La prensa. 1941- . 1942.

Directores: P. A. Cuadra, J. Pasos.

Véase: Carter, 179.

Nuevos Horizontes. Managua. 1941-1947. (UT).

Directora: M. T. Sánchez.

Véase: Carter, 180.

Cuadernos del Taller San lucas. Granada. Irregular. I, 1, 18 octubre 1942-5, agosto 1951. (TU).

Directores: S. Cardenal Argüello, P. A. Cuadra, E. Mejía Sánchez. Propósito: "Nuestros 'Cuadernos' no tienen intención de revista. Son tomos de una biblioteca de cultura católica nicaragüense."

Véase: Carter, 177-178.

Letras. Managua. Mensual. 1943-1946.

Director: A. González y Moncada.

ARgos. Managua. Quincenario literario. 1944.

RUBÉN DARío. Managua. Revista quincenal literaria. 1944-.

Director: F. Rodríguez (Pbro.).

IDEAS. Managua. Revista literaria popular. Mensual. 1953-.

Director propietario: S. Fonseca Ruiz.

Véase: Carter, 176.

Orto. Managua. Órgano de la Asociación de Escritores y Artistas Americanos.

Bimensual. 1956-.

Director: F. Buitrago M.

Véase: Carter, 176-177.

El Pez y la Serpiente. Managua. Trimestral. 1961-.

Director: P. A. Cuadra.

Prospecto: "El Pez y la Serpiente significan, en primer lugar, la dualidad de este país de lagos y volcanes y la 'armonía áspera' de que habló Rubén Darío... El Pez y la Serpiente significan también las dos historias-la indigena y la hispana-cuya confluencia, fusionando culturas y mestizando razas, formó la historia del pueblo nicaragüense: Por tierra peregrinaron las razas y pueblos aborígenes que formaron la base étnica de Nicaragua y en sus teogonías y en sus artes y en el misterio de sus representaciones la Serpiente fue el símbolo clave... Por el agua nave- 
garon y llegaron los hispanos... Y por el agua del mar y del bautismo nos llegó el Pez, que es Cristo. Pero el Pez y la Serpiente significan también la lucha del Bien y del Mal y la agonía del escritor contemporáneo en su difícil y dramático testimonio..." No firmado (pero es de P. A. C.).

Autores: T. Merton, "Boris Pasternak y las gentes con Leontina"; E. Cardenal, traductor de "Salmos"; C. A. Sáenz, "Quetzalcóatl en Centro América"; E. Mejía Sánchez, "Boleros" (poemas); P. A. Cuadra, "Agosto" (cuento); E. Pound, "Aves y no"; E. Gutiérrez, "¿Hacia dónde va la pintura moderna?"

Comentario: Revista que refleja el pensamiento del grupo católico nicaragüense de escritores e intelectuales.

\section{SUPLEMENTO}

Véase la Bibliografia de trabajos publicados en Nicaragua, Managua, Nuevos Horizontes, 1944-1948, de la Serie Bibliográfica de la Biblioteca Americana de Nicaragua, números 1-9 (1943-1947), la cual incluye secciones de revistas y periódicos publicados en el país durante ese período. Entre otras publicaciones periódicas citadas, las siguientes bien pudieran ser de interés para el investigador literario: Ateneo (1943), La antorcha (1943-1947).

Véanse también las notas biográficas de Poesia nicaragüense, Managua, Nuevos Horizontes, 1948, las cuales llevan muchas referencias a revistas literarias en donde han colaborado los poetas que figuran en la antologia.

Recuérdase aqui la magnífica contribución de Darío al periodismo hispánico en todas partes del mundo occidental. Dos revistas saltan a la memoria cuanto antes: la Revista de América, que fundó con R. J. Freyre en Buenos Aires en 1894, y Mundial Magazine (París, 1911-1919; véase Carter, UCLA; UN), de la cual fue director literario.

\section{PANAMA}

EL Cosmos. Panamá. 1896-1897.

Fundador y ditector: G. Andreve. 
Autores: A. Dutary, A. García, D. Herrera, S. Rivas, L. A. Soto. Comentario: "Típica tribuna modernista." Carter, 181.

El Heraldo del Istmo. Panamá. Semanario. 1904-1906.

Fundador, propietario y director: G. Andreve.

Autores: S. Argüello, Darío, J. Flórez, Nervo, L. C. López, Ugarte, G. Valencia.

Comentario: Calificada como "nuestra primera revista de letras..." en cuyas páginas "tuvo eco sonoro el modernismo entonces en su apogeo." Nuevos Rrtos. Panamá. 1907-1917.

Fundador y director: R. Miró.

Comentario: Una de las revistas literarias de más larga vida, y de más fama que ha habido en el país. Fue, en efecto, una prolongación de El heraldo del Istmo.

Esto Y AQuello. Panamá. Revista literaria. 1915-1916.

Director: E. Geenzier.

La Revista Nueva. Panamá. Artes y ciencias. Mensual. I, 1, mayó 1916-VI, 2, febrero 1919. (LC, 5 tomos).

Director: J. D. Moscote.

Gerente: M. Marzo Ruiz.

Propósito: "Ha nacido del pensamiento, por mucho tiempo acariciado, de crear un órgano de cultura que, en su más genuino alcance, sea algo así como el idearium de la patria panameña... Las ciencias, la literatura y las artes constituirán el campo de sus especulaciones."

Autores: A. Andrade Coello, G. Andreve, Barrès, Bergson, Boutroux, E. Carrere, A. Coester, J. D. Crespo, Darío, Dewey, J. P. Duncan, D. Fábrega, J. A. Facio, E. Faguet, M. Flores Cabrera, N. Garay, E. Geenzier**, A. Gómez Restrepo; J. González Scarpetta, M. Grillo, R. Gutieri, M. Henríquez Ureña, Heredia (francés), G. O. Hernández, J. Isaacs, D. Korsi, Maeterlinck, G. McKay, O. Méndez Pereira*, D. Mendoza, R. Miró*, Molière, G. Muñoz Medina, J. M. Pinilla Urrutia, F. Quirós y Quirós, Rodó, M. Roy, C. Saavedra Zárate, Santa-Teresa, J. A. Silva, R. Sotela.

Comentario: Llaman la atención en especial los siguientes trabajos: J. González Scarpetta, "Ricardo Miró" (mayo 1916); F. Quirós y Quirós, "Sobre el castellano en Panamá (fonología)" (julio 1917) y "Cuestiones lingüísticas (enseñanzas de la gramática)" (julio-agosto 1918); M. Roy, estudio sobre La gloria de Don Ramiro; G. McKay, "Renovación lite- 
raria" (agosto 1917), que trata de la literatura panameña; A. Gómez Restrepo, "Un soneto célebre" (septiembre 1917), atribuido a Santa Teresa; J. D. Crespo, "Rodó y el americanismo" (diciembre 1917); O. Méndez Pereira, "Ensayo de semántica general y aplicada al lenguaje panameño" (octubre 1918); D. Korsi, sobre E. Carrere (octubre 1918); J. A. Facio, una larga y nutrida "Carta literaria" sobre literatura costarricense (diciembre 1918); y M. Grillo, un largo estudio sobre J. Isaacs. R. Sotela traduce el ensayo de A. Coester sobre "El movimiento modernista" (febrero 1919) y M. Henríquez Ureña traduce a Heredia. J. P. Duncan escribe una serie de artículos sobre libros y escritores franceses (sobre Barrès y Boutroux, entre otros). Inclúyense muchos discursos dictados ante el Instituto Nacional de Panamá. La mayoría de éstos tratan de temas educacionales, sociológicos e históricos, pero los hay también que versan sobre asuntos literarios. La Sección Bibliográfica contiene unas buenas reseñas sobre libros tanto extranjeros como nacionales.

J. D. Moscote, el único director hasta enero de 1917, cuando se junta con él $O$. Méndez Pereira como codirector, fue vicerrector del Instituto Nacional. Cada número lleva índice. De interés para el comparatista y para el historiador literario. Véase: Leavitt.

EL Mundo. Panamá. Revista mensual ilustrada. Ciencias, artes, literatura, comercio, industrias y variedades. 1922-1930. (BCP; LC, 1 tomo, marzo 1928-octubre 1929).

Director: N. Arce.

Redactor: J. Oller.

Autores: Coppée, J. Francés, V. García Calderón, E. Gómez Carrillo, Hugo, J. Ingenieros, M. Machado, R. Miró, Musset, Nervo, Poe, Rodó.

Comentario: Hacia 1928, V. A. de León S. y J. Pastor Paredes se juntan al cuerpo de los redactores. Es una revista del tipo antológico; contiene poca crítica literaria de valor. Los escritores extranjeros representados en sus páginas son los consagrados de otra época. $Y$, en general, los nacionales son poetas de fama local. De escaso valor literario y de muy reducido interés para el comparatista.

Universidad de Panamá. Trimestral. 1936-1957. (LC; PAU; UCLA).

Director: O. Méndez Pereira.

Véase: Carter.

Épocas. Panamá. 1947-1952. (UT). 
Tierra Firme. Panamá. I, 1, enero 1952-.

Director: R. H. Jurado.

Autores: D. Korsi, R. Sinán.

Comentario: De excepcional importancia para la nueva poesía, este periódico cultural de artes y letras fue publicación de la Dirección de Cultura y Bibliotecas. Un alarde de modernidad tipográfica.

Letras de Panamá. Panamá. Revista literaria. I, 1, diciembre 1957-. Director: D. de la Rosa.

Subdirector: A. Menéndez Franco.

Véase: Carter.

\section{SUPLEMENTO}

Véase: Carter (181-182), para otras publicaciones periódicas que bien pudieran ser de interés para el investigador literario: El céfiro (1866), El crepúsculo (1870), El cronista (1878), El estudio (1879), El ancón (1882), El estímulo (1890), La revista gris (1892-1896), El duende (1893), La nube (1893), El lápiz (1894), Para nosotros (1940-1942), Byblos (1954-1956), Policromía (1954-1956), Clarin (1955-1956), Revista cosmopolita (1955-1956), Carátulas (1956), Nuestra América (1956-1957).

Véase también R. Miró, Cien años de poesía en Panamá (1852. 1952), Panamá, Ministerio de Educación, 1953, quien en muchos casos cita las publicaciones periódicas en donde encontró algunos de los poemas de su antología.

\section{PARAGUAY}

EL Porvenir. Asunción. 1882. (UT).

Véase: Carter, 150.

Revista del Paraguay. Buenos Aires. 1891-1898. (U'T).

Véase: Carter, 150; Leavitt.

Revista del Instituto Paraguayo. Asunción. 1896-1909. (UT).

Director: B. Rivarola.

Véase: Carter; Leavitt.

Revista del Paraguay. Asunción. Historia, letras y arte, ciencia, filosofía, americanismo. Bimestral. I, 1, enero-febrero 1913-I, 6, diciembre 1913. (UCLA; UT). 
Fundadores: V. Díaz-Pérez, R. Lara Castro.

Propósito: "Propónese... además, y muy preferentemente, divulgar los conocimientos de la historia patria ... y hablará del movimiento de libros y publicaciones en general, despertando y fomentando el intercambio de relaciones culturales entre el nuestro y los demás países..."

Comentario: Como reza el "Propósito", se da máxima importancia a la historia. Aparte la sección "Revistas" y las notas bibliográficas, lo único apenas que pudiera interesar al investigador literario es el artículo de V. Díaz-Pérez sobre S. Rusiñol.

CRónICA. Asunción. 1913-1915. (UT).

Véase: Carter, 150.

Letras. Asunción. Mensual. 1915-1916. (BNA, 1 tomo; UT).

Director: M. Riquelme.

Autores: V. Díaz-Pérez, M. Domínguez, J. E. O'Leary, I. A. Pane, Poe, Tagore, O. Wilde, P. M. Ynsfrán.

Comentatio: Revista de carácter modernista, de interés para el comparatista. Véase: Carter.

Pórtico. Asunción. 1919. (UT).

Véase: Carter, 150.

Revista Paraguaya. Asunción. 1925-1928. (UT).

Véase: Carter, 150.

Revista del ateneo Paraguayo. Asunción. 1940-1943. (UT).

Véase: Carter, 150.

\section{SUPLEMENTO}

Citando a Centurión (III, 411-414). Carter (150) menciona los siguientes órganos literarios "lanzados por los socios de los "Centros Estudiantiles'": Aleteos, Apis, Ariel, El colibri, El combate, El estudiante, Fibra, Ibis, Ideal, Minerva, Pegaso, La semana.

\section{PERÚ}

La Revista de Lima. Quincenal. I, 1, 15 junio 1860-VI, 1, 1 julio 1862. (UCLA).

Director: J. C. Ulloa. 
Redactores: N. Alayza, E. Althaus, M. Ålvarez, F. Barriga Alvarez, P. J. Calderón, J. V. Camacho, Luciano B. Cisneros, Luis B. Cisneros, M. N. Corpancho, A. Flórez, M. A. Fuentes, E. Gómez Sánchez, M. Irigoyen, J. A. de Lavalle, F. Lazo, A. Leubel, F. Masías, I. Noboa, T. Pacheco, M. Pardo, M. M. Rivas, P. J. Saavedra, J. S. Tejeda.

Prospecto: "... las Revistas han llenado un vacío y correspondido a una necesidad; fácil es reconocer cuanto mayor es la de su aclimatación en un país como el nuestro, que casi puede decirse que carece de prensa, cuya literatura está aún en la infancia, en el que la aparición del libro está rodeada de tantas dificultades y tropiezos, y que sin embargo tanto necesita de prensa y de libros, porque todo está en él por crear, en la política como en la historia, en la administración como en literatura, en las ciencias como en las artes... la Revista de Lima no es un periódico con bandera ni de sistema, no es conservadora ni liberal, romántica ni positivista, proteccionista ni abolicionista. Sin más norte que el bien público y sin más objeto que el adelanto y progreso del país, insertará artículos de todas escuelas ... contendrá principalmente cuadros históricos, biográficos y alguna vez de costumbres, estudios políticos, científicos, literarios y artísticos, artículos económicos sobre moneda, cambio, huano, industria, caminos de hierro y otros asuntos prácticos de interés general, de cuando en cuando versos y novelas y siempre una crónica de los sucesos públicos de la quincena; pero todos estos escritos serán nacionales por su origen y sus tendencias, y cuando así no lo sean, serán poco conocidos entre nosotros."

Autores: Beranger*, R. J. Bustamante (1845), J. V. Camacho***, S. Camacho ("Nazareno")*, M. N. Corpancho*, A. Elpidos, Espronceda (canto inédito de "El diablo mundo"), J. A. García y García, J. H. García de Quevedo, J. M. Gorriti**, Hugo** (largo estudio sobre el poeta y sus últimas poesías, por I. Noboa; y traducciones hechas por R. Palma y F. Pardo [1827]), E. Lillo, J. A. Márquez, B. Mitre (poesías), Montagine, Olmedo (poesías inéditas), R. Palma***, F. Pardo, J. Pardo, P. Paz Soldán y Unanue, P. Pereira Gamboa, C. A. Salaverry, Shakespeare (crítica y traducción de una escena de Hamlet, por I. Noboa).

Comentario: Importante revista que vale ser consultada sólo por las contribuciones de R. Palma, entre las cuales figuran poesías, leyendas, tradiciones, crítica (sobre B. Mitre, J. M. Gutiérrez), traducciones (de Hugo), trozos de los Anales, notas bibliográficas, crónicas, etc. Otro infatigable colaborador fue J. V. Camacho, quien se puso también a cul- 
tivar la tradición y quien contribuyó con un largo estudio sobre Metastasio. Interesan también el trabajo de M. N. Corpancho sobre poesías inéditas de Olmedo, el estudio de J. M. Gutiérrez sobre Juan Caviedes (reproducido del Comercio de Lima donde salió anónimo por el año de 1852); y el trabajo de J. A. de Lavalle sobre el Poema bistórico sobre la fundación y grandezas de Lima del padre Rodrigol de Valdez. De especial interés también son las crónicas políticas, literarias y teatrales $\mathrm{y}$ las revistas de la quincena. Cumple fielmente con el programa anunciado en el "Prospecto". Cada tomo lleva un "índice por orden de materias". Revista fundamental para saber de la vida intelectual y cultural de Lima de aquella época.

El Correo del Perú. Lima. I, 16 septiembre 1871-VII, 4 febrero 1877.

Comentario: "...el mejor periódico literario editado en Lima en el siglo pasado." Colaboraron en él las figuras más destacadas en letras e historia hispanoamericanas. J. T. Medina publicó en él sus primeros trabajos.

Revista Peruana. Lima. I, 1, enero 1879-V, 30 mayo 1880. (HU;

IC; NYP; UC; UCLA; UNC; UT).

Fundador: M. F. Paz Soldán.

Editor: C. Paz Soldán.

Autores: S. Camacho, M. González de la Rosa, J. A. de Lavalle, S. Lorente, R. Palma, J. T. Polo, J. C. Ulloa, F. C. Zegarra.

Comentario: Publica documentos históricos y literarios de gran valor y valiosos trabajos sobre prehistoria, arqueología y lingüística. Interesa en especial la sección "Biblioteca peruana", editada por M. F. Paz Soldán, la cual proporciona datos valiosos sobre las publicaciones periódicas del país. Palma contribuye con unas 45 tradiciones. Terminó con la ocupación de Lima por las tropas chilenas. Véase: Leavitt.

La Revista Social. Lima. 1885-1888.

Comentario: "Vocero del 'Círculo Literario', de la primera concentración postromántica en torno a González Prada... una literatura de transición, vacilaciones, tanteos y luces crepusculares." En él se encuentran las primeras palabras de Darío publicadas en el Perú. Véase: E. Núñez, "Las generaciones postrománticas del Perú", Letras, 5(1936), 412-426. 
El Ateneo de Lima. Mensual-quincenal. I, 1, enero 1886-ViII, 96, diciembre 1889. (HU; UCLA).

Comentario: "El antiguo 'Club Literario', en sus tres folletos de Anales (1873-1874, 1875-1876 y 1885), reúne parte de sus trabajos; pero 'El Ateneo de Lima', habiendo ensanchado su esfera de acción, juzga insuficiente la forma de anales y funda hoy una publicación a estilo de las llamadas revistas." Indices. Sumario de revistas. Presenta una lista de publicaciones periódicas que salen a luz en Lima en 1886. Éstas suman un total de 23 , de las cuales 6 son diarios y 17 son revistas. La más antigua es El comercio (diario), fundada en 1839. Las demás son casi todas de los '80. Ninguna parece ser "literaria". Se habla de una segunda época entre 1900 y 1914, de la cual no he visto ningún número. Véase: Leavitt.

Er Picaflor. Lima. Decenario de lectura amena dedicado a la juventud. I, 1, 1 enero $1888-I, 36,30$ diciembre 1888.

FIN DE SIGLO. Lima. Semanario. 1890.

Autores: Chocano, E. López Albújar, C. Palma.

América Ilustrada. Lima. Semanario literario artístico. I, 1, 24 mayo 1890-I, 13, 24 agosto 1890. (UCLA).

Administrador: J. J. Outrans.

Prospecto: "Nuestro semanario, además, tiende a unir con los robustos lazos del pensamiento a este vastísimo continente... $\mathrm{E}$ insertando en él los trozos escogidos de todos los literatos americanos, sus biografías y sus retratos... a la par que los de aquellos que por sus virtudes cívicas brillen notablemente, los haremos estimables por sus obras..."

Autores: Bolivar, G. Gómez de la Avellaneda, J. D. Guarín ("David"), Lamartine, E. Lillo, C. A. López, A. Lozano, M. M. Luna, M. Melgar, R. Núñez, Olmedo, R. Palma, F. Pardo y Aliaga, J. de D. Peza, J. M. Rivas Groot, San Martín, Schiller, R. E. G. de Sologuren, Taine, C. A. Torres.

Comentario: Poesía, cuadros de costumbres, revista de teatros, variedades. Nada de crítica literaría. R. E. G. de Sologuren traduce a Taine; C. A. López traduce "La repartición de la tierra" de Schiller. Muchas contribuciones son de escritores obscuros, principalmente de Bolivia y del Perú. Grabados, con biografías, de Bolívar, R. Núñez, San Martín, y otros. De escaso interés para el comparatista. 
El Perú Ilustrado. Lima. 1890-1897.

Director: M. Moncloa y Covarrubias.

Autores: Chocano, C. Palma, Ulloa.

Comentario: Chocano dirigió un solo número en 1890. Volvió a ser director en 1895. C. Palma traduce a Richepin y escribe sobre Della Rocca de Vergalo. Fue una de tantas revistas de la segunda concentración postromántica en torno a Chocano a partir de 1895.

El Perú Artístico. Lima. 1890-1900.

EL IRIS. Lima. 1894.

Director: C. Palma.

Comentario: De muy especial interés para un conocimiento de los comienzos del modernismo en el Perú es el artículo de C. Palma sobre "La decadencia en América".

La Neblina. Lima. Artes y letras. 1896-1897.

Director, editor y propietario: J. S. Chocano.

Autores: E. A. Carrillo, E. López Albújar, F. Mostajo, C. Palma.

Comentario: Fue en sus páginas (núms. I2, I3 y I4) donde F. Mostajo publicó su largo e histórico trabajo sobre "Los modernistas peruanos" y donde Chocano lanzó el manifiesto: "Creeremos y esperaremos en manifestaciones genuinamente nacionales", en su ensayo sobre "Poesía nacional". (5 abril 1896).

La Revista Literaria. Arequipa. 1897.

La Gran Revista. Lima. 1897-1898.

Director: J. S. Chocano.

Comentario: De la segunda concentración postromática en torno a Chocano a partir de 1895. Véase: E. Núñez, "Las generaciones postrománticas del Perü", Letras, 5(1936), 412-426.

El Modernismo. Lima. 1900.

La Ilustración Peruana. Lima. 1900-1914.

Comentario: Dentro de la modalidad modernista. C. Palma figura entre los colaboradores.

Lima Ilustrado. 1901.

Comentario: Interesa el artículo de M. Moncloa sobre "Los bohemios de 1886". 
Prisma. Lima. Revista ilustrada, de artes, letras, etc. Quincenal. I, 1, 15 septiembre 1905-III, 71, 28 diciembre 1907. (UCLA).

Directores: J. S. Hernández, C. Palma.

Autores: M. Acuña, C. G. Amézaga, Baudelaire*, M. Beingolea, Blanco-Fombona, Campoamor, Carducci (en el original), Chocano**, Darío**, Daudet*, L. Díaz, A. France, J. Gálvez***, F. García Calderó, V. García Calderón, E. Gómez Carrillo, Gutiérrez Nájera, Heredia (en el original francés), J. S. Hernández**, D. Herrera, Leconte de L'Isle-Adam, J. Lorrain, Lugones, N. P. Llona, Maeterlinck (en el original), J. A. Márquez, Martí, Maupassant, C. Mendès, M. Moncloa y Covarrubias (M. Cloamón), Nervo*, Nủñez de Arce, C. Palma***, R. Palma**, F. Pardo y Aliaga, J. de la Riva Agüero, S. Rueda*, S. Rusinol, Mark 'Twain, Villaespesa, E. Zamacois.

Comentario: La revista ilustrada y literaria más importante del Perú de la época modernista. En sus páginas se publica el clásico ensayo sobre la literatura del Perú independiente de J. de la Riva Agüero. C. Palma comenta sobre producciones literarias y artísticas desde su página "Notas de artes y letras". Y M. Moncloa y Covarrubias firma su página teatral con el seudónimo "M. Cloamón". Premiada con Medalla de Plata en la Exposición Internacional de Milản de 1906.

El "Prospecto", de 52 páginas ilustradas, salió a luz el 16 de agosto de 1905, un mes antes del primer número, con "materiales acumulados desde la segunda quincena de julio... como muestra y prospecto de lo que pronto vamos a realizar."

Biografía Minerva. Lima. Revista mensual ilustrada de literatura y artes, ciencias e industrias. I, 1906-III, 1908.

VARIEDADES. Lima. 1908-1924.

Comentario: ". . la revista Variedades, única que hasta este día de la aparición de Colónida ha mantenido un discreto culto por la tradición literaria, ya que muy fugaz fue la vida de otras, publicó un artículo o información referente a la personalidad de un peruano cuyo nombre y cuyo genio parecían definitivamente esfumados en el misterio: Della Rocca de Vergalo, extraño y convencido profeta de muchas innovaciones y aspectos de la poesía modernista." A. Ulloa Sotomayor, en' Colónida, I (1916), 5.

CONTEMPoráneos. Lima. Quincenal. I, 1, 1 abril 1909-I, 12, 1 octubre 1909. 
Directores: E. Bustamante y Ballivián, J. A. Hernández.

Comentario: Revista que propagó y defendió al modernismo. Véase el estudio por A. Tauro, "Contemporáneos y Cultura, dos revistas de la generación modernista", en Letras, 9 (1938), 134-155, el cual of rece un índice completo de la revista.

Cultura. Lima. Mensual. I, 1, julio 1915-I, 3, septiembre 1915.

Director: E. Bustamante y Balliviản.

Comentario: "A Cultura le tocó perfeccionar la experiencia de Contemporáneos bajo la influencia de la notable madurez poética alcanzada por Enrique Bustamante y Ballivián, a quien una repentina enfermedad le impidió ampliar y proseguir la sazonada empresa literaria que empezó a cumplir su revista." A. Tauro, Contemporáneos y Culiura, dos revistas de la generación modernista", Letras, 9 (1938), 135. El estudio contiene un índice completo del contenido de la revista.

ArIEL. Arequipa. 1915-1916.

LuLU. Lima. 1915-1916.

Colónida. Lima. Revista quincenal de literatura, arte, historia y ciencias sociales. I, 1, 15 enero 1916-I, 4, 1 mayo 1916. (UCLA). Director: A. Valdelomar.

Autores: P. Abril de Vivero, A. Aguirre Morales ("Literatos jóvenes de Arequipa"), Baudelaire ("L'Albatros", en el original y en traducción española de E. Marquina), E. Bustamante y Ballivián, E. A. Carrillo, Chocano, A. N. Della Rocca de Vergalo, J. M. Eguren, P. Ferrari ("Cosmopolitismo", en el original y en traducción española de M. González Prada), A. France ("Ames obscures", en el original y en traducción española de F. T. Llado), V. García Calderón ("La literatura peruana", reproducido de La revue hispanique), P. Gibson, A. González Prada, Heredia ("Les conquérants", en el original francés), J. C. Mariátegui, F. More, Rodó, A. Ulloa Sotomayor, A. Valdelomar.

Comentario: Hay secciones tituladas: "La quincena literaria", "Quincena artística", "Quincena teatral". La portada de distintos números lleva retratos de Chocano, Eguren y otros.

"La generación llamada 'colónida' ... hace suya el ánima y el módulo del simbolismo francés... Es en Gibson, en Bustamante, en Valdelomar, en Vallejo..., en quienes se logra la más jugosa cosecha literaria de carácter simbólico..." de la literatura peruana. 
Véase: A. Tauro, "Colónida en el modernismo peruano" y "Bibliografía de Colónida", en la Revista iberoamericana, I (1939), 77-82, 461-467.

El Mercurio Peruano. Lima. Revista mensual de ciencias sociales y letras. I, 1, julio 1918-. (HU; LC; PAU; UC; UCLA; UT).

Director: V. A. Belaúnde.

Comentario: Suspendido entre 1931 y 1939. Véase: Carter; Leavitt. $Y$ también: Indice general del Mercurio peruano, tirada aparte, XXVI, 219, 1945, 31 pp.; J. de la Riva Agüero, "Los veinticinco años de nuestro Mercurio", XXV, 197, 1943, 348-360; y V. A. Belaúnde, "Los cuarenta años del Mercurio peruano, XXXIX, 375, 1958, 275-283.

Studium. Lima. Mensual. 1919-1921.

Comentario: Publicación de la Federación de Estudiantes del Perú. Importante para saber del ambiente intelectual y universitario de aquel entonces. Interesante material gráfico.

MUNDIAL. Lima. 1920-1925.

Boletín Biblıográfico. Lima. I, 1, julio 1923-XXIV, 1-4, diciembre 1954. (UCLA).

Fundador: P. S. Zulen.

Directores: J. Basadre, M. García Calderón, E. Romero, J. M. Valega, L. Varela Orbegoso.

Autores: X. Abril, M. Adán, R. Alberti, J. Basadre, Byron (y Espronceda, II, 1925-1926), J. Carrera Andrade, C. Córdoba F., J. Díez Canseco, J. Gálvez, P. Gibson, A. González Prada, J. Jiménez Borja, I. A. Leonard (sobre Petalta Barnuevo, XI-XII, 1941), J. C. Mariátegui (sobre W. Frank, R. Rolland, B. Shaw, II, 1925-1926), A. Miró Quesada S., Neruda, E. Núñez, Ortega y Gasset, R. Palma, R. Porras Barrenechea, L. A. Sánchez, A. Tauro, J. C. Tello, F. del Valle, ValleInclán, C. Vallejo, P. S. Zulen.

Comentario: Publicado por la Biblioteca de la Universidad Mayor de San Marcos. Contiene discursos, registros, estadísticas, bibliografías. Importante es la sección "Libros y folletos peruanos publicados..." anualmente. $\mathrm{La}$ "Selección de artículos publicados en revistas y periódicos nacionales, llegados a la Biblioteca..." se inicia en 1939, debida a la abnegada labor de C. Córdoba F., D. García Ramos y A. Benavides Balbín continuándose cassi ininterrumpidamente hasta I953. Ințeresạn tam: 
bién las dos listas preparadas por A. Tumba Ortega: "Revistas peruanas publicadas en el segundo semestre de 1942 y en el año 1943" (XIV, 1943, 278-308) y "Periódicos nacionales del siglo xIX, que existen en la Biblioteca Central de la Universidad Nacional Mayor de San Marcos" (XIV, 1944, y ss.). De excepcional interés para fines de este trabajo es el estudio de A. Tauro sobre "4 revistas de tono menor" (X, 1940, 286-322), acompañado de un índice completo del contenido de las mismas. Las revistas son: Abecedario (1929-1930), Bolivar (1930-1931), Horario (1930) y Presente (1930). Y de interés también es el artículo titulado "Las revistas peruanas en 1937", VIII (1938), 17-25, en el cual, bajo "Letras y filología", se citan sólo dos revistas, Letras y Sphinx. Leemos lo siguiente en el mencionado artículo: "Desde la época en que D. Mariano Felipe Paz Soldán publicó su 'Biblioteca Peruana', en el año de la guerra con Chile, no se había hecho probablemente una bibliografía de las publicaciones periódicas nacionales. Para el estudiante de nuestra cultura, el conocimiento de la producción periódica es indispensable. La cantidad de libros y folletos editados en el Perú es muy pequeña y no refleja ciertamente la integridad de nuestro movimiento cultural..."

Novecientos. Lima. Revista mensual de arte, literatura, historia y ciencias sociales. 1924.

Comentario: Parece que hubo sólo seis números.

Amauta. Lima. Doctrina, arte, literatura, polémica. I, 1, septiembre 1926-IV, 32, agosto-septiembre 1930. (LC; TU; UCLA; UT).

Director: J. C. Mariátegui.

Propósito: "Esta revista... es la voz de un movimiento y de una generación ... cribará a los hombres de la vanguardia-militantes y simpatizantes-hasta separar la paja del grano ... El objeto... es el de plantear, esclarecer y conocer los problemas peruanos desde puntos de vista doctrinarios y científicos. Pero consideraremos siempre al Perú dentro del panorama del mundo... El título no traduce sino nuestra adhesión a la Raza, no refleja sino nuestro homenaje al Incaísmo".

Autores: X. Abril, M. Azuela, H. Barbusse, J. Basadre, S. Delmar, J. M. Eguren, I. Ehrenburg, W. Frank, M. González-Prada, A. Guillén, Haya de la Torre, E. López Albújar, R. Martínez de la Torre, G. Mistral, Neruda, Ortega y Gasset, J. Parra del Riego, B. Pilniak, M. Portal, L. A. Sánchez, M. Seoane, Shaw, Shelley, Stalin, Trotski, Unamuno, L. E, Vaḷcárcel, C. Vallejo, Vasconcelos, M. Wiessę, 
Comentario: Interesa ver una traducción de Shelley por E. Dieste, curiosa anomalía literaria entre tanto material polémico que se destaca más y más por su acentuado tono marxista o anti-imperialista. La lista de los colaboradores en sí es garantía de tal tendencia izquierdista y vanguardista, confirmando la observación de que en torno a Amauta "se agruparon todos aquellos elementos que en aquellos años deseaban una renovación de las ideas y un cambio radical en el enfoque de los problemas sociales." Son muchos los artículos sobre arte y literatura rusos, y extensa la colaboración o representación de ideas, letras y escritores rusos. El trabajo de Mariátegui sobre Defensa del Marxismo establece el tono de los últimos números de la revista, la cual deja de publicarse con su muerte en 1930. Son pocos los escritores de otros países hispanoamericanos que contribuyen durante los últimos años. Justo es observar que Amauta sigue "de gran actualidad porque muchas de las ideas expresadas en sus artículos sólo se van realizando en estos días." Por su indole, en cierto modo revolucionario, muchos de sus números fueron confiscados. Indudablemente fue la mejor revista de tendencia marxista de aquella época, la más representativa y la que más influencia ejerciera por todo el mundo hispánico.

Hay que mencionar que también colaboraron en ella los más destacados artistas: Camilo Blas, Julia Codesido, los hermanos Izcue, Carmen Saco, José Sabogal, entre otros.

Véase: A. Tauro por un índice de los primeros años (1926-1930) de Amauta, publicado en el Boletín bibliográfico de la Universidad de San Marcos, 11-12 (1938-1939), 163-184, 46-113. Véase: Carter.

LA Sierra. Lima. Órgano de la Juventud Renovadora Andina. Revista mensual de letras, ciencias, arte, historia, ciencias sociales y polémica. I, 1927-IV, 1930.

Comentario: En esta revista toman forma, por primera vez, las diferentes corrientes del indigenismo.

Nueva Revista Peruana. Lima. Bimestral, I, 1, 1 agosto 1929-II, 5, 1 abril 1930. (UCLA).

Directores: M. Ibérico, A. Ulloa, A. Ureta.

Propósito: " ... aspira a ser una publicación de actualidad... Estudiaremos, entre otras, la cuestión social... Con ello cumpliremos un intenso voto de juventud... Creemos en la nacionalidad y la consagramos como un valor primario," 
Autores: M. Adán, L. Alayza y Paz Soldán, C. Bambarén, J. Basadre, M. Ibérico (sobre Unamuno), A. Miró Quesada Sosa, E. Núñez, L. A. Sánchez, A. Ureta (sobre A. Godoy), E. A. Westphalen.

Comentario: Consta de estudios; crónicas literarias, políticas, científicas y artísticas; notas; informaciones y comentarios; y documentos. Hay índices para cada tomo.

Letras. Lima. I, 1, 1929-1959. (UCLA).

Director: J. Gálvez.

Autores: A. Alonso, J. Basadre, M. Beltroy, E. Bustamante y Ballivián, E. Champión, Faulkner, W. Frank, A. Gide, J. R. Jiménez, J. Jiménez Borja (sobre Góngora), I. A. Leonard, A. Miró Quesada Sosa, E. Núñez, E. O’Neill, E. Peña, M. Picón Salas, L. A. Sánchez, A. Sánchez Reulet, Sarmiento, A. Tamayo Vargas, A. Tauro, A. Ureta (sobre Tolstoi), L. F. Xammar.

Comentario: Órgano de la Facultad de Letras y Pedagogía de la Universidad Mayor de San Marcos. Sólida revista de estudios académicos en materia de literatura, filosofía, historia y arqueología. Salió cada cuatro meses. Suspendida entre 1930-1936. Importantes para el estudio de las revistas literarias en el Perú son: E. Núñez, "Las generaciones postrománticas del Perü", 5 (1936), 412-426; y A. Tauro, "Contemporáneos y Cultura, dos revistas de la generación modernista", 9 (1938), 134155. Véase: J. M. B. Farfán, Indice del contenido de la revista Letras, Lima, 1941, 76 pp. (hasta el número 17); y D. Valcárcel, Indice de la revista Letras, el cual corresponde a los años 1929-1954.

SpHINX. Lima. Bimensual. I, 1, 1937-IV, 13, 1940. (UCLA).

Comentario: Revista bimensual del Instituto Superior de Lingüística y Filología de la Universidad Mayor de San Marcos. Importantes contribuciones para la filología y la lingüística y para el estudio del quechua y del folklore.

Huamanga. Ayacucho. Revista trimestral. I, 1, diciembre 1937-XIII, 1949. (UCLA).

Directores: N. J. Gálvez Carrillo, L. Milón Bendezú.

Comentario: Órgano del Centro Cultural de Ayacucho. Revista que refleja la vida cultural del Sur del Perú, conteniendo artículos sobre la historia, el folklore y las letras del Departamento de Ayacucho.

Los Nuevos. Lima. Revista bimestral de literatura, arte y crítica, 1938. Dirẹctor: J. S. Abugattás, 
Tres. Lima. I, julio 1939--III, diciembre 1941. (UCLA).

Directores: J. A. Hernández, A. Jiménez Borja, L. F. Xammar.

Cultura Peruana. Lima. Revista bimestral ilustrada. I, 1, encro-febrero 1941 -XIX, 138, diciembre 1959. (UCLA; UT).

Fundadores: J. Flores Araoz, A. Jochamowitz.

Director-gerente: J. Flores Araoz.

Propósitos: "... es un órgano integralmente independiente, dedicado al servicio del intelecto donde quiera que se encuentre y venga de donde viniere, siempre que esté inspirado en elevados ideales de sana afirmación nacionalista... Procurará seguir el ritmo espiritual del momento... reseñando y difundiendo los nuevos aportes a la ciencia, la literatura, la plástica, la música, la poesía..."

Autores: X. Abril, M. Adán, C. Alegría, R. Arciniega, A. Arias Larreta, J. Basadre, Bécquer, C. G. Belli, M. Beltroy, Cecilia Bustamante, Chocano, Darío, J. M. Eguren, J. Ferrando, J. Gálvez, J. A. Hernández, A. Malraux, A. Miró Quesada Sosa, Neruda, E. Núñez, C. Palma, R. Palma, L. A. Paz Soldán, C. Pellicer, R. Porras Barrenechea, Prescott, J. de la Riva Agüero, Fernando Romero, W. Saroyan, A. Tamayo Vargas, A. Tauro, A. Valdelomar, C. Vallejo, M. Vargas Llosa, E. Vázquez, L. F. Xammar.

Comentario: Empezó como bimestral, convirtiéndose en mensual. Estudios sobre la historia, el arte y la literatura del Perú. Ensayos de crítica literaria. Reproducciones fotográficas del arte peruano. De interés especial para el comparatista son: las traducciones de "Poesía contemporánea francesa" (A. Breton, R. Char, R. Desnos, P. Eluard, P. Emmanuel) (1959) por C. G. Belli; las traducciones de "Poesía contemporánea de los Estados Unidos" (E. E. Cummings, C. H. Ford, L. Hughes, E. Pound, C. Sandburg, K. Shapiro) (1959) por C. G. Belli; y la serie de artículos sobre "La actualidad literaria y artística en el mundo" de los últimos años.

Historia. Lima. Bimestral. I, 1943-III, 1945. (UCKA).

Director: J. Basadre.

Comentario: Publica trabajos importantes sobre política, historia, sociología, economía, literatura y folklore.

IPNA. Lima. Órgano del Instituto Cultural Peruano Norteamericano. Cuatrimestral. 1944-. (UCLA; UN; U'T). Véase: Carter. 
FÉnIX. Lima. Revista de la Biblioteca Nacional. I, 1944-XII, 1957. (UCLA).

Director: J. Basadre (1944-1948), C. de Losada y Puga (19491957.

Redacción: A. Tauro.

Autores: J. T. Medina, Ovidio, R. Palma, Emilia Romero, L. F. Xammar.

SAN Marcos. Lima. Revista de cultura general. I, 1, julio-agosto 1947II, 5, julio-septiembre 1948. (UCLA).

Autores: G. Bernanos, Cervantes, F. Cossío del Pomar, J. Gabriel, J. de Ibarbourou, J. Jiméncz Borja, A. Maurois, F. Mostajo, E. Núñez, G. Owen, E. Peña, P. Salinas, L. A. Sánchez, A. Siegfried, F. Tamayo, A. Tamayo Vargas, A. Tauro, C. Vallejo.

Comentario: Editada por el Instituto de Periodismo de la Universidad Nacional Mayor de San Marcos de Lima. De alta calidad académica y literaria y "un dechado periodístico". De especial interés para la historia de la literatura peruana es la reproducción del célebre estudio de F. Mostajo sobre "Los modernistas peruanos". Véase La neblina, 1896. 1897.

Las Moradas. Lima. Revista de las artes y las letras. I, 1, 1947-III, 7-8, enero-julio 1949. (UCLA; UN).

Director: E. A. Westphalen.

Comité de redacción: T. Acosta M., C. Cueto Fernandini, E. Solati Swayne, F. de Szyszlo.

Autores: M. Adán, J. M. Arguedas, H. Delgado, T. Dreiser, J. Durand, T. S. Eliot, Hidegger, H. James, J. Joyce, E. Mejía Sánchez, A. Miró Quesada Sosa, E. Peña, Proust, P. Reverdy, A. Reyes, Sartre, A. Wagner de Reyna, L. Zea.

Comentario: Revista que está al par de lo más nuevo en estética y filosofía occidentales; muchas traducciones del francés y del inglés; importante para el comparatista. Véase: Carter.

MAR Del Sur. Lima. Revista peruana de cultura. Bimestral. I, 1, septiembre 1948-V, 30, diciembre 1953. (UCLA; UN; UT).

Director: A. Miró Quesada Sosa.

Redactores: L. J. Cisneros, P. Gibson, F, Miró Quesada, M. Solari Swayne, A. Tauro.

Véase: Carterer. 
IDEA. Lima. Revista ilustrada de artes y letras. Trimestral. I, 1, enero 1950-VIII, 33, 1957.

Director: M. Suárez Miraval.

Letras Peruanas. Lima. Revista de humanidades. Semanario. I, 1, 1951-II, 7, 1952. (UCLA).

Director: J. Puccinelli.

Cuadernos Trimestrales de Poesía. Trujillo. 1952-.

Director: M. A. Corcuera.

Comentario: Ofrece no sólo poesía peruana sino también hispanoamericana y con menos frecuencia, francesa e italiana. De tendencia ecléctica. Han salido unos 23 números.

La Novela Peruana. Lima. Mensual. 1953.

Comentario: Publicado por el Círculo de Novelistas Peruanos. Sólo aparecieron dos números, correspodientes a octubre y noviembre de 1953.

Generación. Lima. Revista de letras, artes y ciencias. Bimestral. 19531954.

Director: M. A. Capuñay.

Literatura. Lima. 1958-1959.

Directores: L. Loayza, A. Oquendo, M. Vargas Llosa.

\section{SUPLEMENTO}

No he podido precisar ni el lugar ni las fechas de publicación de las revistas Búcaro americano y Pluma y tinia. Serán de fines del siglo pasado cuando hubo "cincuenta publicaciones periódicas literarias entre 1884-1902." Véase: E. Núñez "Las generaciones postrománticas del Perú", loc. cit., 146.

Véase: M. A. Fuentes, Biblioteca peruana de bistoria, ciencias $y$ literatura... Antiguo Mercurio peruano. Lima, 1861, 4 tomos, para una reedición del célebre Mercurio peruano (1791-1794), órgano de la Sociedad Académica de Amantes del País y "la más antigua de las revistas de América".

Cito, por excepción, las siguientes revistas que presentan aspectos de interés para el investigador literario:

Anuario Biblográfico Peruano. Lima. 1943-1954. (UCLA).

Editor: A. Tauro. 
Comentario: Publicación de la Biblioteca Nacional, proporciona excelentes materiales en las secciones sobre folklore, filología y lingüística, y literatura. Muy útiles son los índices onomásticos y los índices de publicaciones periódicas.

Boletín de la Biblioteca Nacional. Lima. I, 1, octubre 1943-XII, 17-18, 1955. (UCLA).

Director: J. Basadre.

Comentario: Bibliografías, discursos, índices, informes, registros. De mayor interés es la sección de "Publicaciones periódicas aparecidas en el Perú durante los años de 1943 y 1944" (I, 160, 284, 398).

Boletín Del INSTITUto RIVA-AgÜERo. Lima. 1951-1957. (UCLA).

Comentario: Publicación de la Pontífica Universidad Católica del Perú. No es propiamente dicho una publicación periódica, pero sí contiene estudios de importancia para las letras.

Es justo recordar aquí la contribución al periodismo hispánico en el extranjero hecha por F. García Calderón como director de La revista de América en París de 1912 a 1914. Véase: Carter; UCLA; UN.

\section{PUERTO RICO}

Almanaque - Aguinaldo de la Isla de Puerto-Rico. San Juan. Anual. 1859-1889. (APR).

Comentario: Estos "aguinaldos" sirven muy bien como reflejo de la producción literaria y de los intereses literarios de los puertorriqueños durante el largo período que antecede a la aparición de la Revista puertorriqueña (1887-1893). Cada número anuncia los títulos que están en venta en la Librería de Acosta, los cuales son los mismos de las librerías españolas de la Península. La mayoría de las contribuciones originales son de origen puertorriqueño o peninsular. Por lo que respecta a las letras extranjeras, hay estudios y traducciones de la poesía anónima alemana y también de la poesía francesa e inglesa; notables entre los nombres representativos de la literatura extranjera son: Byron (ChildeHarold, por D. M. de la Peña, editada en Nueva York); Florián, por J. N. Gallego; Franklin; Gautier ("La nube", traducción de M. Elzaburu, I887); Hugo; Humboldt; Krummacher; Metastasio; Richter; Stedman. De interés para el comparatista y para el historiador de la cultura puertorriqueña. 
Revista Puertorroueña. San Juan. Literatura, ciencias y artes. 18871893. (UPR).

Director: M. Fernández Juncos.

Autores: A. Alcardi, Amicis, Arnaud, F. Arvers, Banville, Barbier, E. de la Barra, Bécquer*, Bourget*, Byron, Carducci*, Castelar, Castello Branco, Claretie, Clarín, Coppée, J. Courteline, T. Critt, Dante, Darío, Daudet, João de Deus, Díaz Mirón, Dinis, Dumas hijo, Eça de Queiroz, M. Elzaburu, A. France, L. García-Ramón, Gautier, E. de Goncourt, H. Greville, Guerra Junqueiro, Gutiérrez Nájera, Heine*, Heredia (francés), T. Hood, Hugo, J. Isaacs, Lamartine, A. Langlois*, E. Legouvé, Lenáu, J. Lermina, Loti, Maupassant, R. M. Merchán, Millevoye, F. Mistral*, Molière*, T. Moore, E. Paillerón, R. Palma, B. Paoli, Pardo Bazán, Pérez Galdós, J. O. Picón, Pushkin, B. W. Richardson, Richepin, L. Rolland, Rückert, S. Rueda, M. Sánchez Pesquera, Saint-Victor, P. Sandor, V. Sardou, A. Scholl, E. Schuré, J. Simón, S. Smiles, Stendhal, Sully-Prudhomme, Taine*, A. Theuriet, P. C. Timothée, Tolstoi*, Valera, N. Vog, Zola.

Comentario: Una de las mejores revistas literarias hispanoamericanas de la época, especialmente por el interés manifestado en las letras extranjeras. En este sentido cabe notar que dedica regularmente una sección a las "Letras y artes en París" y otra a la literatura peninsular. También llama la atención el espacio que da a la literatura portuguesa; el mismo director $M$. Fernández Juncos se encarga de las traducciones hechas de Castello Branco, João de Deus, Dinis, Eça de Queiroz, Guerra Junqueiro y otros. La sección francesa, dirigida por L. García-Ramón desde París, contiene excelente material sobre todos los géneros literarios y sobre los escritores principales de la literatura francesa. Los nombres que llevan asterisco han sido objeto de sendos estudios críticos. Vale precisar más con respecto a algunos de los muchos autores traducidos: M. Elzaburu traduce a Gautier ("Afinidades secretas", 1888; "Sinfonía en blanco mayor", 1888 y 1890; "El humo", 1888); el mismo director Fernández Juncos traduce a Coppée, a Richepin ("El mendigo", 1888; "Natividad", 1888; "La torre gigante", 1889); P. C. Timothée también traduce a Gautier ("El pabellón acuático" 1889); y E. de la Barra traduce a Heredia ("La víspera", 1893). Cabe mencionar también el largo estudio de L. García-Ramón sobre Richepin. Otras traducciones notadas al azar son: T. Hood, "Canción de la camisa", traducción anónima, fechada en 1890, encabezada por las palabras "Literatura socialista"; T. 
Moore, "En la noche callada", por J. Isaacs en 1892; F. Mistral traducido por Daudet; y S. Smiles, "La sociedad de los libros", anónima. Se reproduce además el conocido trabajo de R. M. Merchán sobre "Bécquer y Heine", 1889. Hay traducciones también por M. Sánchez Pesquera sacadas de su libro aún inédito, Ecos extranjeros. Este extraordinario interés en la literatura extranjera es un reflejo ya de la presencia del espíritu modernista en la Isla. Voces modernistas de otros países hispanoamericanos se hacen escuchar ya en sus páginas, las de Darío, Díaz Mirón, Gutiérrez Nájera. Pero poco o nada de esta nueva manera se nota aún en la obra de los colaboradores puertorriqueños mismos, a no ser que sea, claro está, la curiosidad que muestran ellos por conocer la producción literaria del exterior.

Cosmos. Yauco. Revista decenal ilustrada de ciencias, artes, literatura, noticias y anuncios. I, 10 julio 1903-II, 20 mayo 1904. (UPR). Comentario: Las contadas traducciones son todas del inglés. M. Cordero traduce "El arroyo" de Tennyson; M. N. Yordán traduce "¡Adiós a junio!" de H. M. Richardson. Se traduce a C. M. Lowe. De escaso valor literario, y exceptuando lo arriba indicado, de poco interés para el comparatista.

Puerto Rico Ilustrado. San Juan. 1910-1952.

Revista DE las ANTIllas. San Juan. Magazine hispano-americano. Ilustrado. I, 1, marzo 1913-II, 9, noviembre 1914. Mensual. (UPR). Director: L. Lloréns Torres.

Subdirector: M. Abril.

Propósito: "Nuestra Revista hablará en las Antillas de la cultura del mundo, y en el mundo de la cultura de las Antillas".

Autores: Baudelaire, A. Bennett, Byron, R. Canales, Carlyle, C. Coll y Toste, F. Crane, P. Déroulede, M. Elzaburu, Gautier, P. González Blanco, M. Guerra Mondragón, Hauptmann, Omar Khayyam, Kipling, Körner, Maeterlinck, J. Maragall, Mauclair, F. Ménétrier, F. Mistral, Ovidio, Sully-Prudhomme, Verlaine, O. Wilde.

Comentario: Extraordinario interés en la literatura extranjera. C. Coll y Toste traduce a Omar Khayyam; M. Elzaburu traduce la "Sinfonía en blanco mayor" de Gautier; P. González Blanco traduce "Stump Orator" ("Elocuencia política") de Carlyle; M. Guerra-Mondragón traduce "Salomé" de O. Wilde; y hay una traducción de "María Magdalena" 
de Maeterlinck por L (uis) D(elgado) C(orrea). Hay traducciones, además, de Baudelaire, de A. Bennett, de F. Crane, de P. Déroulede, de Kipling, de Körner, de J. Maragall, de Mauclair, de F. Ménétrier, de F. Mistral, de Ovidio, de Verlaine y de las literaturas oriental, árabe, húngara y portuguesa. N. R. Canales edita una sección titulada "Vendimia literaria", en que se ofrecen noticias e informes sobre autores (Byron, Hauptmann, et al.) y acontecimientos literarios. Contiene buenos datos bibliográficos y buenas ilustraciones. Revista en que floreció el modernismo $y$, en general, la poesía moderna en la Isla. En ella, también, Lloréns Torres llega a definir su nueva modalidad estética que bautizó con el nombre de "pancalismo". De gran influencia e importancia literaria y de gran interés para el comparatista.

Puerto Rico. San Juan. Mensual. I, 1, mayo 1919-.

Alma Popular. San Juan. Revista literaria ilustrada. 1925-1927. (UPR).

Comentario: He visto sólo dos números. De poco interés para el comparatista.

Revista de Estudios Hispánicos. Río Piedras-Nueva York-Madrid.

Trimestral. I, 1, enero 1928-II, junio 1929. (UCLA).

Director: F. de Onís.

Comentario: Predecesor del Boletín del Instituto de las Españas Carter).

(1931-1934) y de la Revista bispánica moderna (1934-; véase

Prisma. Humacao. Mensual. 1928-1929.

INDICE. San Juan. Mensual. 1929-1931.

Ámbrto. Río Piedras. La revista que defiende el pensamiento actual. 1934-1936. (UPR).

Autores: M. Arce, J. A. Balseiro, C. Meléndez, L. M. Morales, L. A. Nazario, A. S. Pedreira.

Comentario: Es, como reza el subtítulo, revista de pensamiento actual; de interés para, el comparatista a pesar de que no of rece traducciones ni crítica de otras literaturas.

Ateneo Puertorriqueño. San Juan. Trimestral. I, 1, enero 1935IV, 4, diciembre 1940. (UCLA; UPR).

Redactores: M. Arce, E. S. Belaval, V. Geigel-Polanco, R. Lavandero, M. Meléndez Muñoz, S. R. Quiñones, N. Vientos. 
Cartel: " ... esta revista ... amanece... como continuación de la que, hace treinta años, editara el Ateneo Puertorriqueño a iniciativa de su entonces presidente Doctor M. Quevedo Báez."

Autores: M. Arce, M. T. Babín, T. Blanco, Hostos, E. A. Laguerre, Lloréns Torres, C. Meléndez, L. Palés Matos, A. S. Pedreira, ValleInclán, $M$. Zeno Gandía.

Comentario: El órgano literario más reciente del Ateneo Puertorriqueño. Cabe notar que se fundó el Ateneo el 29 de junio de 1876. Los materiales son casi todos de origen o de interés local. Empero, hay reseñas de libros extranjeros y de vez en cuando una crítica o traducción de obras de otra lengua. Llama la atención el trabajo de M. T. Babín sobre el "Toi et moi" de P. Géraldy. De especial interés es el homenaje a A. S. Pedreira (III, 3, 1939).

El Día Estético. Ponce. 1, 1, junio 1941-1943.

Comentario: Órgano de los "integralistas", cuyo propósito fue: "... hacer un llamado a los poetas del país hacia la creación de una poesía puertorriqueña de carácter telúrico ... no adormilarnos en un regionalismo pintoresco de limitaciones, y sí universalizarnos en lo vital nuestro. Bautizamos este movimiento con un nombre de ancho contenido: Integralismo." Cf. Rosa-Nieves, 265.

Insula. San Juan. 1941-1943.

Comentario: Otro órgano de los "integralistas".

Asomante. San Juan. Trimestral, 1945-. (TU; UC; UCLA; UT). Véase: Carter.

Alma Antillana. San Juan. La revista de las antillas. Mensual. 1948-. Director: J. A. Ayéndez.

Pegaso. San Juan. 1952.

Comentario: Órgano del "trascendentalismo".

Mundial. San Juan. Revista de artes y letras. 1953-.

Director: A. Tefel.

LA Torre. Río Piedras. Trimestral. 1953-. (UCLA; UPR; UT).

Véase: Carter.

Orfeo. Ponce. Revista de letras. Semestral. 1954-1957.

Director: R. Zapata Acosta.

Comentario: Órgano del "trascendentalismo", y publicación de la Universidad Católica Ponce. 
Revista del Instituto de Cultura Puertorrqueña. San Juan. Trimestral. I, 1, octubre-diciembre 1958-. (UCLA).

Autores: F. Arriví, J. A. Corretjer, J. de Diego, E. A. Laguerre, C. Lair, F. Manrique Cabrera, R. Marqués, C. Meléndez, E. F. Mendoza, L. Muñoz Rivera, L. Palés Matos, J. Rivera de Álvarez, C. RosaNieves.

Comentario: Trabajos sobre arquitectura, filología, historia, literatura, música. De literatura hay poesía original, cuentos, crítica. También estudios sobre el teatro y el folklore. Hay un homenaje a L. Palés Matos (3, abril-junio, 1959). Y un largo trabajo sobre L. Muñoz Rivera (4, julio-septiembre, 1959). Excelente revista de cultura isleña.

\section{SUPLEMENTO}

Rosa-Nieves (271-272) cita otras revistas, evidentemente literarias, sin más datos que los de nombre y fechas: Los seis (1924); Alma latina (1930-); Bruijula (1934-1937); Bayoann (1950-1951); Hélices (19501953); Poesia (1953); Artes y letras (1953-).

\section{REPÚBLICA DOMINICANA}

El .LÁPIZ. Santo Domingo. 1891-1892. (URD).

EL Hogar. Santo Domingo. 1894.

Fundador: F. Fiallo.

Directores: F. Fiallo, T. M. Cestero.

Ciencias, Artes y Letras. Santo Domingo. 1896.

Letras y Ciencias. Santo Domingo. Quincenal. 1898-1899.

Fundador y director: F. Henríquez y Carvajal.

Revista Ilustrada. Santo Domingo. 1898-1900. (URD).

EL IBIs. Santo Domingo. 1900.

Director: F. Henríquez Ureña.

Autores: M. Henríquez Ureña, P. Henríquez Ureña, Porfirio Herrera, B. Iglesias, M. Mazara, A. Perdomo.

PágrNAs. Santo Domingo. 1900.

Director: J. E. Buñols.

Autores: F. Henríquez Ureña, M. Henríquez Ureña, P. Henríquez Ureña. 
Prosa y Verso. San Pedro de Macorís. 1900.

Directores: L. Bermúdez, G. F. Deligne, R. A. Deligne.

LA TARDE. Santo Domingo. 1900.

Fundador: M. Henríquez Ureña.

Revista Literaria. Santo Domingo. 1900-1901.

Director: E. Deschamps.

Autores: F. Henríquez Ureña, M. Henríquez Ureña, P. Henríquez Ureña.

El Faro Literario. Santo Domingo. Semanal. 1901.

Fundador y director: $M$. Henríquez Ureña.

Comentario: Es versión posterior de La tarde.

EL IdEAL. Santo Domingo. Semanal. 1901. (URD).

Fundador: M. Henríquez Ureña.

Autores: P. Henríquez Ureña, J. T. Mejía h., A. Pérez Perdomo.

Comentario: Órgano del Ateneo de la Juventud. De corta vida.

Nuevas Páginas. Santo Domingo. 1901.

Comentario: El ibis y Páginas, y sus respectivos colaboradores, se juntan para formar Nuevas páginas.

La Patria. Santo Domingo. Semanal. 1901.

Fundador: P. Henríquez Ureña.

Comentario: Contiene las primicias literarias, ensayos y estudios, del fundador.

Santo Domingo. Publicación quincenal de ciencias, artes y letras. I, 1, 23 marzo 1901-I, 10, 31 octubre 1901.

Santo Domingo Intelectual. Macorís de Este. 1903-1904.

Director: H. de Marchena.

La Cuna de América. Santo Domingo. Revista de ciencias, artes y letras. Semanario. 1903-1932. (HU; URD).

Autores: R. Arévalo Martínez, J. Austen (traducida por P. Henríquez Ureña), O. Bazil, T. M. Cestero, Chocano, Darío, G. F. Daligne, F. Fiallo, F. García Godoy, Gocthe, Hauptmann (traducido por M. Hentíquez Ureña), Heine (traducido por Palma), F. Hentíquez y Carvajal, Primitivo Herrera, P. Louys (traducido por J. R. Jiménez), A. 
Lugo, Lloréns Torres, G. Mistral, Nervo, L. Rodríguez de Tió, Shaw ("Triunfo del 'Positivismo'", marzo 1922), J. A. Silva, Valle-Inclán.

Comentario: Una de las revistas más importantes y de más larga vida del país. Refleja bien las tendencias literarias continentales de aquellos años. De más valor para las letras antes de 1930. Después se puso cada día más popular, de noticiero ilustrado, y hasta con fotos de cinelandia. Pero hasta el final siguió guardando una página para poesía y un cuento semanal.

El Album. Santiago de los Caballeros. 1906-1907.

OsiRIs. Santo Domingo. Revista de artes y letras. Quincenario. 1 noviembre 1909-. 1 febrero 1911. (BAGN).

Director: V. Giró.

Autores: Baudelaire, Coppée, D’Annunzio, Darío, Eça de Queiroz, F. Fiallo, A. France, F. García Godoy, Gómez Carrillo, E. González Martínez, R. de Gourmont, M. Henríquez Ureña, P. Henríquez Ureña, Ibsen, J. R. Jiménez, Longfellow, P. Louys, T. Llorente, F. T. Marinetti, C. Mendès, R. Miró, Moréas, Nietzsche, Renán, Rodó, S. Rusiñol, SullyPrudhomme, Laurent Tailhade, Ugarte, S. Ureña de Henríquez, G. Valencia, R. H. Valle, Valle-Inclán, Verlaine, Villaespesa, O. Wilde.

Comentario: Revista del movimiento modernista en el país; la gran cantidad de traducciones refleja el extraordinario interés en las letras extranjeras: Gómez Carrillo escribe sobre Oscar Wilde; E. González Martínez traduce "Nocturno" de Moréas; M. Hentíquez Ureña traduce "Encuentro" de Ibsen; T. Llorente traduce "Don Juan de los infiernos", de Baudelaire, y "Mármoles" de Sully-Prudhomme; G. Valencia traduce "Agonía" de Verlaine.

Además de los escritores citados, son muchos los nacionales que contribuyen a la revista. Importante para demostrar hasta qué punto y hasta qué período el modernismo siguió dominando en la expresión literaria de los distintos países y regiones de las Américas. De especial interés para el comparatista.

Mireya. San Pedro de Macorís. 1910. (URD).

Ateneo. Santo Domingo. Mensual. Marzo 1910- junio 1913. (URD).

Director: F. Henríquez y Carvajal.

Autores: D. M. Borrero, Chocano, Darío, F. García Calderón, Heine, M. Henríquez Ureña, P. Henriquez Ureña, Lloréns Torres, Martí, A. Reyes, Rodenbach, Ugarte, Uhland, R. H. Valle. 
Comentario: Quizá la mejor revista literaria, cultural e intelectual del país; de intereses continentales y hasta universales; de plena época modernista. Llama la atención el artículo de M. Henríquez Ureña sobre Rodenbach. Como órgano del Ateneo Dominicano fue fruto, en gran parte, de la labor de su presidente, F. Henriquez y Carvajal.

El Estudio. Santo Domingo. 1911. (URD).

QUisqueYA. Santo Domingo. 1913. (URD).

LETRAs. Santo Domingo. 1917. (URD).

Crisantemos. Santo Domingo. Revista miscelánea. 1917-1918. (URD).

Director: A. R. Lamarche.

Comentario: Otra revista nacional-y no cito los escritores nacionales que siguen mayormente influenciados por el modernismo-que sigue recogiendo el trabajo de los maestros de aquellos años. De un modernismo retrasado. Además de Dario y de Nervo, hay reflejos de Bécquer. Y G. Valencia traduce "Las manos" de D'Annunzio mientras se traduce un artículo de Amicis sobre D'Annunzio.

Alma Antillana. San Pedro de Macorís. Revista literaria. Quincenario. Enero 1921 - mayo 1921. (URD).

Comentario: Muchas contribuciones puertorriqueñas; algunas de otros países hispanoamericanos; nada del extranjero. Otro ejemplo del tipo de revista regional que fue fruto de un modernismo retrasado. De escasa o ninguna importancia para el comparatista, aunque sí para quien quicra estudiar el movimiento modernista en toda la extensión de su desarrollo en las Américas.

ANARKos. Santiago. Revista literaria. Mensual. Octubre 1923- diciembre 1923. (URD).

Comentario: Hay contribuciones de L. Díaz, Eça de Queiroz, Hugo; inclúyense algunos ejemplos de la poesía "postumista"; nótanse reflejos de Bécquer y Darío. En parte, es revista de un modernismo retrasado, con algunos intentos de ponerse al día con la literatura de vanguardia. De escasa importancia para el comparatista.

ArIEL. Santo Domingo. Revista mensual ilustrada. 1924-1925. (URD). Director: J. M. Pineda.

Autores: E. Carrere, Darío, Díaz Mirón, A. France, Lugones, Rodó, J. A. Silva, Verlaine. 
Comentario: No cito los escritores nacionales. Otra revista nacional cuyo valor principal estriba en que recoge los últimos destellos del modernismo en plena época vanguardista. Nada de crítica ni de evaluación literaria. Cabe notar que E. Carrere traduce a Verlaine.

Cromos. Santo Domingo. Revista mensual ilustrada. 1927-1929. (PAU).

Comentario: Irregular, popular y literaria.

Lumen. Santo Domingo. Revista de ciencias y letras. I, 1, septiembre 1929-I, 6, junio 1930. (PAU).

Ahora. Ciudad Trujillo. Revista literaria dominicana. 1943-1947.

Cuadernos Dominicanos de Cultura. Ciudad Trujillo. 1943-1952. (UCLA; UT). Véase: Carter.

La Poesía Sorprendida. Ciudad Trujillo. 1944-1947.

Directores: A. Baeza Flores, E. Fernández Granell, A. Fernández Spencer, F. Gatón Arce, R. A. Henríquez, M. Lebrón Saviñón, F. Mieses Burgos.

Comentario: "Se publicaron 21 números de la revista y 10 cuadernos con obras personales ... fue un movimiento integrador; sus poetas creían en el pasado, pero no sólo en el pasado remoto, sino en el pasado total, que incluye el pasado más reciente... Nunca hasta entonces la poesía dominicana había tenido un contacto tan directo y tan enriquecedor con la poesia inglesa, francesa, norteamericana y española." A. Fernández Spencer, Nueva poesía dominicana, Madrid, Ediciones Cultura Hispánica, 1953. Véase todo el capítulo (18-33) titulado "El postumismo y La poesia sorprendida (1916-1947)."

Revista Dominicana de Cultura. Ciudad Trujillo. 1955-1956. (UC LA; UT). Véase: Carter.

\section{SUPLEMENTO}

No he podido precisar las fechas de publicación de las siguientes revistas: Agora, de Ciudad Trujillo, y Los nuevos, de La Vega, las cuales deben haber sido revistas precursoras del rumbo que iba a tomar la poesía dominicana hacia 1944, con la aparición de La poesía sorprendida.

Ramón Lugo Lovatón, en su trabajo Periódicos dominicanos en el Archivo General de la Nación, Ciudad Trujillo, Editora Montalvo, 1953, cita unas 36 publicaciones periódicas del período 1821-1900, de las 
cuales muchas (diarios, semanarios y quincenarios) of recen material de interés para el investigador literario. Habría que consultar también: el Anuario bibliográfico dominicano, Ciudad Trujillo, 1944-1948, el cual ofrece cada año, una sección aparte para "Periódicos y revistas aparecidos"; la Antologia de la literatura dominicana, Santiago, Ediciones del gobierno dominicano, 1944, 2 tomos, la cual presenta una excelente lista de periódicos y revistas en el primer tomo (325-339); y el nutrido capitulo sobre "El periodismo y la oratoria" (252-290) por M. Henríquez Ureña en su Panorama bistórico de la literatura dominicana, Río, 1945.

\section{EL SALVADOR}

LA Juventud. San Salvador. Revista de El Salvador. Literatura, ciencias, bellas artes. Mensual. 1880-1883. (BNS).

Director: J. Méndez.

Autores: M. Acuña* ("Ante un cadáver"), H. C. Andersen, L. A. Baralt, Bécquer*, J. J. Bernal*, E. Blasco, Byron, R. Cabrera, J. A. Calcaño, Camoens, Campoamor*, M. A. Caro, Castelar, A. Contreras, Chateaubriand, Chenier, Dario*, D. Estrada, B. de Foureroy, F. E. Galindo, A. García Gutiérrez, F. Gavidia*, O. Goldsmith, I. Gómez*, T. Gray, Gutiérrez Nájera*, E. Hall, G. F. Hall, Heine, A. Herculano, Hugo*, A. J. de Irissari, Lamartine, C. Lemonnier, Lessing, Longfellow, Martí, R. Mayorga Rivas*, Menéndez y Pelayo, J. J. Milanés, J. Milla, Montalvo*, T. Moore, Musset, Núñez de Arce*, M. del Palacio, J. J. Palma*, R. Palma, Pérez Bonalde, Petrarca, E. Piñeyro, Poe, R. Pombo, F. Proaño, R. Reyes, L. Rodríguez de Tío, A. Rojas, R. Rosa, I. Ruiz Araujo*, J. Selgas, A. Sellén, Shakespeare, J. Sierra, R. Southey, SullyPrudhomme, A. de Trueba, J. C. del Valle, C. Velado, F. Veralde, J. C. Zenea, Zola.

Comentario: Excelente e importante revista literaria para un estudio de la época premodernista. En ella aparecen nombres y obras, originales y en traducción, de hispanoamericanos y extranjeros, que han de ser como la piedra angular de la nueva modalidad estética. Compara más que favorablemente con otras revistas hispanoamericanas de la época. Llaman la atención: la traducción de Musset por D. Estrada; Petrarca en traducción de A. García Gutiérrez; Ia "Elegía" de Gray traducida por I. Gómez; "El ermitaño" de O. Goldsmith traducido por E. Hall; 
el homenaje a J. Milla; y Lessing traducido por F. Sellén. De muy especial interés son los poemas de Gutiérrez Nájera, "Carta abierta" y "Por la ventana", reproducidos de El Porvenir de Guatemala y La paz de Tegucigalpa, respectivamente, en respuesta a la pregunta: "¿Quién es Gutiérrez Nájera?"”

La BNS contiene desde el tomo II, enero 1881 hasta el tomo V, 22 julio 1883, inclusive. Durante 1882-1883 la revista salió cada dos semanas.

Repertorio Salvadoreño. San Salvador. Mensual de la Academia de

Ciencias y Bellas Letras de San Salvador. I, 1, 15 agosto 1888VII, 4, diciembre 1892. (BNS).

Directores: J. Bertis, F. Castañeda, F. A. Gavidia, C. Velado (18881889); V. Acosta (IV, 2 febrero 1890- junio 1890); J. Bertis, F. A. Gavidia; J. Bertis, B. Calderón, J. A. Delgado, F. A. Gamboa (V, 1, enero 1891); D. González, A. Lima; F. A. Gamboa, F. Martínez Suárez (1892).

Autores: V. Acosta, I. E. Arciniegas, M. A. Caro, Coppée, Chocano, Darío, Díaz Mirón, Dickens, F. Gavidia, Hugo*, A. Masferrer, C. Matto de Turner, R. M. Merchán, M. Soto Hall, Mark Twain, C. Velado, Whitman, Zola*.

Comentario: Muy importante para los orígenes del modernismo en Centro América y especialmente para V. Acosta, Darío, Gavidia y los escritores extranjeros cuya influencia determinó el rumbo que tomara la nueva modalidad literaria. Revista bien equilibrada de intereses nacionales, continentales y europeos. Importante para el comparatista. La revista deja de aparecer entre junio y diciembre de 1890 debido a la ausencia de F. de Gavidia que se había ido a Costa Rica a principios de septiembre de 1890 , "donde piensa radicarse".

La Juventud Salvadoreña. San Salvador. Revista mensual de la Sociedad Científico-Literaria del mismo nombre. I, 1, junio 1889-VII. 9, septiembre 1897. (BNS).

Redactores: A. Chavarría, H. R. Jarquín, V. M. Jerez.

Editor responsable: F. A. Reyes.

Autores: A. Ambrogi, I. E. Arciniegas, E. de la Barra, Carducci, M. A. Caro, Casal, Darío, Derzhavin, Díaz Mirón, R. E. Durón, I. Gamboa*, F. Gavidia, R. W. Gilder, Gutiérrez Nájera, Hugo*, Lamartine, Longfellow, A. Masferter, R. Mayorga Rivas, C. Mendès, Menéndez y 
Pelayo, R. M. Merchán, T. Moore, R. Núñez, R. Obligado, J. J. Palma, Pérez Bonalde, Petrarca, A. Pierra y Agüero, S. Rueda, M. Sánchez Pesquera, Schiller, A. Sellén, Shelley, J. A. Silva, Tasso, Tennyson, Tolstoi, Turguenev, Uhland, E. J. Varona, Zappi, Zola.

Comentario: Revista plenamente dentro ya de la modalidad modernista. Llaman la atención: un acróstico de Darío; Shelley traducido por Menéndez y Pelayo; la oda "A Dios" del poeta ruso Derzhavin, traducido al español por $A$. Pierra y Agüero a través de la traducción inglesa de J. Bowring; Uhland traducido por A. Sellén; soneto a R. W. Gilder por R. Mayorga Rivas; 5 sonetos italianos de Petrarca, Carducci, Tasso, Zappi, traducidos por M. A. Caro. T. Moore traducido por R. E. Durón Importante para el comparatista y para el estudiante del modernismo en Hispanoamérica.

La Pluma. San Salvador. Quincenal. I, 6, 27 agosto 1893-III, 1, 20 julio 1894. (BNC).

Redactor y propietario: A. A. Ambrogi.

Autores: S. J. Carazo, Casal, Chocano, Darío, S. Díaz Mirón, F. Gavidia, E. Gómez Carrillo, Heine, D. Herrera, A. Masferrer, C. Matto de Turner, R. Mayorga Rivas, R. Obligado, S. Rueda, Stecchetti, SullyPrudhomme.

Comentario: Empezó como semanario literario; A. Ambrogi y J. A. Solórzano colaboraron como redactores. Una revista plenamente dentro de la modalidad modernista, con nombres ya consagrados del movimiento en su alcance continental y con otros de la América Central que pronto se habían de destacar como los maestros del modernismo de aquellas tierras.

El Pensamiento. San Salvador. Mensual, I, 1894-III, 1896. (BNS). Autores: A. Ambrogi, Baudelaire, Bécquer, Darío, Heine, S. Key Ayala, J. A. Silva.

Comentario: Interesante revista modernista, cuyas páginas cuentan con la típica colaboración literaria de la época, representativa de lo nacional, lo hispanoamericano y lo extranjero. De interés para el comparatista y para el estudiante del modernismo.

LA UNrversidad. San Salvador. Órgano de la Universidad Nacional. Mensual. Serie VII, I, octubre 1896-12, octubre 1897. (LC, 1 tomo).

Director y editor: V. Pérez. 
Autores: A. Cohn, H. Cornejo, F. Gavidia*, Montalvo, Núñez de Arce, J. C. del Valle.

Comentario: La mayoría de los trabajos tienen que ver con asuntos directamente relacionados con la universidad y en lo general versan sobre derecho, ciencias, sociología y otras disciplinas paralelas. Sin embargo, hay unos estudios de interés para quien estudia las letras. A. Cohn escribe sobre "Los simbolistas franceses" (núm. 6) y H. Cornejo escribe sobre "Safo". De escaso interés para el comparatista.

Centroamérica Intelectual. San Salvador. 1903-.

Director: D. S. Meléndez.

Redactores: J. Delgado Prieto, P. Guzmán Trigueros, B. Orozco, A. Peccorini.

Autores: E. Aragón, S. L. Erazo, Alfredo Espino, F. Herrera Velado, S. R. Merlos, M. Quijano Hernández, J. R. Uriarte.

Véase: J. F. Toruño, Desarrollo literario de El Salvador, San Salvador, Ministerio de Cultura, 1958, pp. 201-202.

LA QuincenA. San Salvador. Revista literaria. 1 abril 1903-1905. (BNS, 4 tomos).

Redactores: V. Acosta, S. I. Barberena, I. Gamboa, F. Gavidia, R. Mayorga Rivas, C. Velado.

Autores: Carducci, Casal, Coppée, Darío, L. Diaz, D. Estrada, Gutiérrez Nájera, Heine, Hugo, Longfellow, Nervo, Poe, J. A. Silva, Verlaine, Whitman.

Comentario: Revista modernista que sigue el rumbo ya marcado por tantas otras en todas pattes del mundo hispano de aquel entonces.

Repertorio del Diario del Salvador. San Salvador. La revista nacional de ciencias, artes, literatura, industria, comercio y agricultura. Quincenal. 1906-1912. (LC, tomos XX-XXI, 113, mayo 1911151, diciembre 1912).

Director: K. Mayorga Rivas.

Administrador: J. M. Lacayo Téllez.

Autores: S. Ålvarez Quintero, I. E. Arciniegas, S. Argüello, V. Aza, Benavente, Blanco-Fombona, Blasco Ibáñez, L. Bonafoux, R. BrenesMesén, B. Byrne, J. J. Cañas, E. Carrere, Casal, E. Castillo, E. de Castro, Coppée, Chocano*, D’Annunzio, Dario*, L. Díaz, Díaz Mirón, DíezCanedo, P. C. Dominici, A. Donoso, Dumas (père), Eça de Queiroz, A. France, J. Francés, Gabriel y Galán, F. García Calderón, F. Gavidia, 
Goethe, E. Gómez Cartillo, G. Gómez de Avellaneda, los Goncourt, C. J. Guerrero, Heine, Heredia (francés), Hugo, A. Insúa, "Jack the Ripper", S. Lagerloff, M. Le Blanc, V. M. Londoño, P. Louys, Lugones, Maeterlinck, T. Martel, A. Martínez Mutis, R. Mayorga Rivas***, V. Medina, C. Mendès, C. de Merode, J. R. Molina, L. Montalbán, A. Muñoz Pérez, Nervo*, R. Nieto, L. E. Nieto Caballero, Nietzsche, E. Noel, J. de J. Núñez y Domínguez, J. J. Palma, R. Palma, R. Pérez de Ayala, M. S. Pichardo, E. Piñeyro, Poe, R. Pombo, M. Prévost, Puig Casauranc, J. Rameau, P. de Répide, A. Rey Soto, L. Rodríguez Embil, S. Rueda, G. A. Ruiz*, Safo, Sanín Cano, M. Serao, J. A. Solórzano, M. Soto Hall, R. Southey, Sully-Prudhomme, Tennyson, Tolstoi, M. de Toro y Gisbert, Turguenev, Ugarte, Unamuno, R. H. Valle, Verlaine, Villaespesa, C. Villafañe, Whitman, O. Wilde, J. F. Zepeda, L. A. Zúñiga.

Comentario: Repertorio, como reza el título, de lo más representativo de la época modernista. Llaman la atención: E. de Castro traducido por B. Byrne; Goethe traducido por F. Gavidia; Heredia traducido por Mayorga Rivas; una paráfrasis de Tennyson por R. Mayorga Rivas; Verlaine traducido por M. S. Pichardo. El folletín del repertorio contiene: T. Martel, Blancafleur, traducida por P. Simón Pineda; M. Prévost, Mi prima Laura, novela, traducida por A. Muñoz Pérez; J. Rameau, Susanita, traducida por M. Toro y Gisbert. Desde el 1 de mayo de 1911 hasta entrado el año 1912 se publica una sección titulada "Vida literaria retrospectiva", que es una especie de "exhumación" de versos centroamericanos del período 1876-1886. He visto sólo lo correspondiente a los años 1911-1912. Importante para el comparatista.

Letras NaCionales. San Salvador. Revista mensual de literatura, industrias, ciencias, artes, agricultura. I, 1, mayo 1908-II, marzo 1909. (BNCR).

Director y propietario: D. A. Hernández.

Comentario: De escaso valor literario, y de ningún interés para el comparatista salvo la presencia de Heine.

Diario del Salvador: Suplemento Literario Dominical. San Salvador. I, 1, 11 septiembre 1910-II, 31, 9 abril 1911. (LC).

Director: R. Mayorga Rivas.

Administrador: J. M. Lacayo Téllez.

Autores: V. Acosta, A. Ambrogi, I. E. Arciniegas, J. R. Avilés, 
Azorín, A. Batres Jáuregui, Baudelaire, Bello, Benavente, Blanco-Fombona, Bodenstedt, J. Bois, Brenes-Mesén, C. de Burgos, B. Byrne, R. Cabrera, Campoamor, S. J. Carazo, E. Castillo, E. de Castro, M. H. Cortés, A. Chenier, Chocano, D'Annunzio, Dario, Daudet, G. D'Esparbés, L. Díaz, J. Diéguez, M. Diéguez, E. Díez-Canedo, F. Fiallo, A. France, J. M. Gabriel y Galán, F. E. Galindo, I. Gamboa, F. Gavidia, T. Gautier, I. Gómez, E. Gómez Haro, A. Gómez Jaime, T. Gray, Guerra Junqueiro, Hartzenbusch, Heine, C. Hispano, E. Houssaye, Ibsen, F. A. de Icaza, "Jack the Ripper"*, F. Jammes, J. R. Jiménez, Kipling, Lamartine, J. Lemaître, P. Lermite, Longfellow, P. Louys, Lugones, Mallarmé, I. Mariscal, Maupassant, R. Mayorga Rivas*, V. Medina, C. Mendès, S. Merrill, J. R. Molina*, Montalvo, Nervo*, R. Nieto, J. J. Palma, S. Pérez Triana, J. de D. Peza, R. Pombo, Richepin, F. Rivas Frade, Rodenbach, Rodó, J. Rodríguez Cerna*, L. Rosado Vega, J. H. Rosny, E. Rostand, S. Rueda, S. Rusiñol, J. M. Salaverría, F. Sassone, J. A. Silva, M. Soto Hall, Sully-Prudhomme, I. Tablanca, Tennyson, A. Theuriet, C. A. Torres, A. Trueba, F. Turcios, Ugarte, L. Urbina, J. R. Uriarte, G. Valencia, J. C. del Valle, Valle-Inclán, S. Velázquez, Verlaine, Villaespesa*, J. C. Zenea, L. A. Zúñiga.

Comentario: Excelente antología de las obras y los autores más representativos del movimiento modernista. Muchas traducciones, pero poca crítica literaria. Llaman la atención: E. Castillo, traductor de F. Jammes, del "Sagramor" de E. de Castro y "La campana" de Rodenbach; M. H. Cortés, traductor de Verlaine; M. Diéguez, traductor de A. Chenier; E. Díz-Canedo, traductor de D'Annunzio; I. Gómez que traduce la "Elegía" de Gray; R. Mayorga Rivas que escribe sobre Tennyson y traduce a Bodenstedt; J. Rodríguez Cerna, sobre Kipling; Uriarte en una imitación de D'Annunzio; G. Valencia que traduce a D'Annunzio; Heine traducido por L. A. Zúñiga. La contribución más larga de todas es la novela corta, Al abismo, del colombiano S. Velázquez. Muy importante para el comparatista.

ATENEO DE EL SAlvador. 1912-. (LC, 3 tomos correspondientes a los años 1927, 1930, 1932; UCLA).

Directores: J. D. Corpeño, F. Gavidia, J. R. Gomar, J. F. Toruño. Véase: Carter.

Mosaico. San Salvador. Revista quincenal de letras, ciencias, artes, comercio. I, 1, junio 1919-IV, 69, agosto 1922. (LC, 1 tomo).

Director: D. Cornejo. 
Autores: A. Ambrogi, Azorín, Baudelaire, R. Barrett, R. Blanco, E. Blasco, Castelar, Chocano, Darío, D. Estrada, F. Gavidia, E. Gómez Carrillo, E. González Martínez, J. de Ibarbourou, J. Ingenieros, D. Ivanovitch, Lamartine, Lessing, María Enriqueta, A. Masferrer, R. Mayorga Rivas, C. Mendès, C. V. Miranda, G. Mistral, Nervo, R. Palma, Richepin, S. Rusiñol, Schiller, J. A. Silva, L. Taboada, Tolstoi, A. TorresRioseco, L. Urbina, J. de Viana, J. C. Zenea, Zola.

Comentario: Todavía dentro de la tradición modernista; del tipo antológico con muchos nombres extranjeros. Los pocos nacionales y centroamericanos son figuras más o menos conocidas. De interés son: una traducción de un fragmento de Lessing hecha por R. Blanco; una imitación del "Cuervo" de Poe en un poema a San Nicolás escrito por D. Estrada para un número especial dedicado a Navidad; "El guante" de Schiller traducido por C. V. Miranda; un articulo de Torres-Rioseco sobre G. Mistral. De poco valor crítico. No hay indicación de las nucvas inquietudes estéticas.

Espiral. San Salvador. Revista del hogar. Ilustrada. Mensual. I, 1, 15 diciembre 1921-II, 34, 15 noviembre 1923. (LC).

Director propietario: M. A. Chacón, E. Lardé.

Secretario: R. de Nufio.

Director artístico: S. Salazar Arrué.

Caricaturista: V. Recinos.

Grabados: F. E. Sasso.

El programa: "Verdad en todo y por todo; Ciencia al alcance de todos...; Belleza en la presentación y en la literatura."

Autores: R. Arenales, C. Bustamante, R. Cansinos-Assens, S. Cañas, A. R. Castro, M. Daireaux, A. Espino*, M. A. Espino, A. France, P. Fort, F. Gavidia, K. Gibran, E. Gómez Carrillo, G. González Contreras, E. González Martínez, Guerra Junqueiro, Heine, P. Henríquez Ureña, Hugo, J. Ingenieros, E. Lardé*, León Aguilera, Lugones, M. Magallanes Moure, Martí, Martinez Sierra, A. Masferrer, C. Mendès, E. Méndez Calzada, F. Miranda Ruano*, G. Mistral, M. Monvel, F. Morán, Nervo, R. de Nufio*, P. M. Obligado, R. Ortega, Ts' In Pao, Pardo Bazán, R. Pérez de Ayala, Poe, Porto-Riche, P. de Répide, C. Reyes, J. E. Rivera, V. Rosales y Rosales, R. A. Salazar, S. Salazar Arrué*, M. Sawa, R. Sotela, Tagore, J. Tallier, J. Torres Bodet, J. R. Uriarte, J. Valdés, G. Valencia, J. Valera, R. H. Valle*, J. Vázquez Mejía, J. A. Velasco, C. C. Vigil, X. Villaurtutia. 
Comentario: Anuncia que publicará artículos por las firmas ya congradas y por los jóvenes, especialmente las damas. Es, pues, más bien una revista para la juventud que no para los ateneístas. Es del tipo antológico de parte de los consagrados y a la vez sirve como órgano de los jóvenes nacionales, pero sin programa marcado y sin haberse identificado todavía con la reacción ultraísta. Hay una sección titulada "Lectura para las damas" en que aparecen trozos de la obra de A. France, Hugo, Lugones, Martí, Martínez Sierra, P. M. Obligado, Pardo Bazán, Tagore, G. Valencia. La sección se disuelve en trozos que andan dispersos por la revista. La obra crítica más importante es la del Dr. R. A. Salazar sobre "Historia del desenvolvimiento intelectual de Guatemala". S. Cañas contribuye con un artículo sobre G. Mistral.

Pensamiento y Acción. San Salvador. Educación, actualidades, difusión de conocimientos útiles y todo lo que constituya elemento de cultura. Mensual. I, 1, 15 julio 1922-III, 5, julio 1926. (LC). Directores: J. Lino, A. Molina.

Autores: Amiel, A. Andrade Coello, Beaumarchais, Benavente, L. Cardoza y Aragón, R. M. Carrasquilla, Casal, Chocano, Darío, Dewey, A. Espino, Gabriel y Galán, G. Gallegos, I. Gamboa, E. González Martínez, Gorki, Herrera y Reissig, Hugo, J. Ingenieros*, Lamartine, R. León, J. Lino Molina***, A. Masferrer, R. Mayorga Rivas, A. Mejía Nieto, Michelet, G. Mistral, J. R. Molina, Montalvo, M. Monvel, Nietzsche, R. Palma, Poe, Quevedo, C. B. Quiroga, S. Rueda, S. Rusiñol, Salarrué, J. M. Salaverría, M. Sánchez Pesquera, B. Sanín Cano, Schopenhauer, F. Turcios, Ugarte, Unamuno, J. R. Uriarte, R. H. Valle, Vasconcelos, J. M. Vergara y Vergara, Villaespesa, Zola.

Comentario: Revista que da considerable espacio a la educación y a las ideas educacionales, lo cual se ve en la cantidad de artículos escritos por Dewey, J. Ingenieros y Vasconcelos. J. Lino Molina contribuye con un estudio sobre Vasconcelos (septiembre 1922). Pocos estudios de interés literario. R. H. Valle escribe sobre "Literatura regional en Centroamérica" (octubre 1922). Hay una sección poética que reproduce selecciones de los poetas más leídos de entonces: Casal, González Martínez, Herrera y Reissig, Villaespesa. No hay indicación alguna de las nuevas modalidades estéticas de postguerra. Indices mensuales y un indice correspondiente al año 1923.

Para Todos. San Salvador. Mensual. I, 1, agosto 1927-III, 18, octubre 1929. (LC, 3 tomos). 
Fundador y director: Dr. M. Zúñiga Idiáquez.

Propósito: Entre diez "aspiraciones" reza la tercera: "Seleccionar la mejor producción de la literatura actual y revivir las... de épocas pasadas..."

Autores: G. Alvarado, A. Andrade Coello, A. Argüello, J. J. Cañas, E. Carrere, A. Coello, Díaz Mirón, Emerson, A. Espino, G. Figueira***, J. García Monge, F. Gavidia, E. González Martínez, G. Gutiérrez González, Heine, Hugo, Lugones, J. Mañach, A. Masferrer***, R. Mayorga Rivas,*, J. R. Molina, J. E. Rivera, S. Salazar Arrué (Salarrué), M. Santa Cruz*, J. A. Silva, R. Sinán, R. Sotela*, Ugarte, R. H. Valle, L. Zúñiga.

Comentario: Hay buenas reseñas de libros salvadoreños y de las letras centroamericanas en general. La sección "Miscelánea" contiene interesantes notas $e$ informes sobre actividades literarias. Poco interés en la literatura extranjera, pero importante para saber de las letras centroamericanas de la época. Reproduce mucho material de Lugones, Mañach (sobre García Monge), Masferrer, Mayorga Rivas (sobre J. J. Cañas), Ugarte. El joven G. Alvarado escribe sobre la leyenda nacional; F. Gavidia traduce a Heine y a Hugo; M. Santa Cruz escribe sobre E. González Martínez. Indice.

Revista Mercurio. San Salvador. Artes, letras, ciencias, industria, comercio. 1938-. (PAU).

Director: J. J. Fernández.

Esfinge. San Salvador. Mensual. I, 1, abril 1945-1946.

Fundador y director: C. M. Arita.

Brisas Nuevas. San Salvador. Mensual. I, 1, marzo 1945-1947.

Comentario: Órgano del Liceo Salvadoreño.

Horizontes. Santa Ana. 1945-1948.

Director: J. Martínez.

Revista de la Biblioteca Nacronal. San Salvador. Cuatrimestral. I, 1, enero-abril 1948-agosto 1949; mayo 1951-agosto 1955. (UCLA). Director: B. Torres.

Redactores: M. J. Arce y Valladares, A. B. Sánchez, Trigueros de León.

Propósitos: "En afán de ofrecer a nuestros lectores no sólo material bibliográfico sino un reflejo fiel de nuestra cultura, publicamos Revista de la Biblioteca Nacional, dejando nuestro Boletín para fines de especia- 
lidad... Letras, artes plásticas, filosofía, historia, ciencias, bibliográficas y noticias forman las diversas secciones. Nos anima el propósito de estimular la producción literaria y artística salvadoreña y centroamericana, sin que por ello estemos divorciados de los movimientos culturales americanos y europeos."

Autores: Claribel Alegría, F. Alegría (sobre Ercilla, T. Mann), M. J. Arce y Valladares, C. Brañas, S. Cañas (sobre A. Masferrer), A. Cardona Peña, A. Casona, (sobre Tirso de Molina), H. Cerezo D. (sobre Barba Jacob), Cervantes (conferencias pronunciadas con motivo de celebrar el cuarto centenario), V. Echeverría del Prado, L. Gallegos Valdés, O-R. González, J. Salvador Guandique (sobre "José Martí, vocación humana"), E. Labrador Ruiz, C. Lars, H. Lindo, J. Mancisidor, S. Quiteño, C. Samayoa Chinchilla, A. Torres-Rioseco, Trigueros de León (sobre R. Alberti), C. Vallejo, A. Velázquez, C. Wyld Ospina.

Comentario: En la sección "Bibliográficas", of récense títulos de. periódicos y revistas publicados durante los años 1945-1948. Sufre una vida algo accidentada, pasando por cinco épocas, con un lapso entre agosto 1949 y mayo 1951, cuando reaparece bajo el nombre de Anaqueles. A pesar de que pierde algo de interés literario en la quinta o última época, seguirá figurando entre las mejores revistas literario-culturales de nuestra época. Artísticamente ilustrada.

ARS. San Salvador. 1951-1954. (UT).

Véase: Carter.

SínTEsis. San Salvador. 1954-1955. (UT).

Véase: Carter.

Cultura, San Salvador. 1955. (UT).

Véase: Carter.

\section{SUPLEMENTO}

Revistas cuyas fechas de publicación no he podido precisar.

Cultura Femenina. San Salvador.

Directora: M. Alvarez.

MUJER. San Salvador.

Directora: M. Álvarez.

SEMANA. San Salvador.

Director: J. L. Urrutia. 


\section{URUGUAY}

LA AUrora. Montevideo. Mensual. I, 1, octubre 1862-junio 1863. Director: J. A. Tavolara.

Comentario: A. Vaillant fue el primero en hacer mención pública del nombre de Renán en el Uruguay. Período de honda crisis de la conciencia católica nacional.

EL IRIS. Montevideo. Quincenal de literatura. I, 1, abril $1864-$

Fundador y director: A. de Vedia.

Comentario: Gran interés en Renán.

LA Revista Literaria. Montevideo. Semanario. 1865-1866.

Director: J. A. Tavolara.

Colaboración: J. Herrera y Obes, J. Jiménez de Aréchaga, R. Montero Bustamante, G. Ramírez, J. P. Varela.

Comentario: Gran interés en Renán.

Anales del Ateneo del Uruguay. Montevideo. 1881-1886; $1947-$ (HU; UCLA; UNC; UT).

Véase: Carter; Leavitt.

Revista DEl Plata. Montevideo. 1882-1883. (UCLA).

Fundadores: A. Terra, D. Terra, J. Jiménez de Aréchaga, A. de Vedia, M. Herrero y Espinosa.

Comentario: Sólo hubo quince números.

Revista de la Sociedad Universitaria. Montevideo. 1884-1885. (HU;

LC; UNC; UT). Véase Leavitt.

Revista Uruguaya. Montevideo. 1892.

Fundador y director: B. Fernández y Medina.

Las Primeras Letras. Montevideo. Ciencias, letras y artes. Quincenal. I, 1892-III, 1894.

Redactores: L. Aguirre, L. A. de Herrera, M. Herrera y Thode, J. A. Ramírez.

Revista Nacional de Literatura y Ciencias Sociales. Montevideo. 1895-1897. (HU; UT).

Véase: Carter; Leavitt; y J. E. Etcheverry, "La Revista nacional (1895-1897)". Número, II, 6-7-8, 1950, pp. 263-286. 
LA Revista. Montevideo. I, 1, agosto 1899-10, julio 1900.

Director: J. Herrera y Reissig.

Comentario: Véase R. Montero Bustamante, "La Revista de Julio Herrera y Reissig", Revist nacional, VIII (agosto 1945), 304-310; y también J. Pereira Rodríguez, "De La revista a La nueva Atlántidd", Numero, II, 6-7-8, 1950, pp. 293-299.

Revista Del Salto. Semanario. I, 1, 11 septiembre 1899-I, 20, 4 febrero 1900.

Director: H. Quiroga.

Comentario: "El semanario no fue totalmente modernista... Pero recogió suficiente cantidad de poemas y relatos de aquella tendencia como para escandalizar no ya a la ciudad del Salto sino a todo el país" E. Rodríguez Monegal, "La Revista del Salto," Número, II, 6-7-8, 1950, pp. 287-292.

Vida Moderna. Montevideo. Literatura, ciencia y arte. Mensual. Primera época: noviembre 1900-septiembre 1903; segunda época: 1910-1911. (HU; LC; UNC; UT).

Directores: J. Lerena Juanicó, R. Montero Bustamante, R. A. Palomeque.

Autores: E. Acevedo Díaz, Bonilla y San Martín, Herrera y Reissig, L. V. Mansilla, A. Nin Frías, Rodó, J. Supervielle, A. A. Vasseur, M. E. Vaz Ferreira, Zorrilla de San Martín.

Comentario: Salen unos 34 números en total. Importante revista de la época modernista. En ella aparecen los primeros versos de J. Supervielle. V'éase: Carter Leavitt.

La Nueva Atlántida. Montevideo. 1907.

Director: J. Herrera y Reissig.

Comentario: Parece que duró sólo dos meses, mayo y junio de 1907. Véase: A. W. Phillips, "Una revista de Herrera y Reissig", Re. vista iberoamericana, XIX (1953), 153-165; y también J. Pereira Rodríguez, "Las revistas literarias de Julio Herrera y Reissig", Revista nacio. nal, XII (diciembro 1949), 345-352, XIII (noviembre 1950), 179-189, y XV (mayo 1952), 205-216.

Revista Rochense. Rocha. Ilustrada de literatura y actualidades. Semanal. 1907-1919. 
Bohemia. Montevideo. Revista de arte. Quincenal. I, 1, 15 agosto 1908III, 44, 30 septiembre 1910. (BNU).

Directores: E. Bianchi, E. Herrera, J. A. Lista.

Autores: D. Agustini, R. Barrett, J. J. Casal, Coppée, Chocano, D’Annunzio, Darío, L. Díaz, Dostoievski, O. Fernández Ríos*, Heine, E. Herrera**, Herrera y Reissig*, Hugo A. Lasplaces**, L. Lasso de la Vega**, J. A. Lista**, Maupassant, C. Mendès, G. Miró, R. Miró, O. Mirbeau, Rodó, S. Rueda, C. Sabat Ercasty, V. A. Salaverri, J. de Viana.

Comentario: Órgano del círculo de los "líticos compañeros" del café "Polo Bamba". Modernista y criollista a la vez. La revista que al principio respondió a la protesta estética de unos jóvenes bohemios se convirtió al fin en "revista nacional ilustrada" que en adelante se iba a llamar Vida nueva. Véase: O. Moratorio, "Ernesto Herrera y el grupo de Bobemia", Revista nacional, XI (1948), 203-226.

Pegaso. Montevideo. Mensual. 1920-.

Comentario: El número 72, correspondiente al año VIII, junio 1924, fue consagrado enteramente a M. E. Vaz Ferreira, con textos inéditos e iconografía y con ensayos de E. Morales, A. Nin Frías, J. Pereira Rodriguez, C. Sabat Ercasty.

Marginalia. Montevideo. 1924-.

Fundador y director: M. Benedetti.

LA CRUz DEL SUR. Montevideo. I, 1, 15 mayo 1924-VI, 34, diciembre 1931. (BNU; 6 tomos).

Director: A. Lasplaces.

Propósito: "Nuestro programa es nuestra obra."

Colaboración: Apollinaire, J. J. Casal, E. Frugoni, J. de Ibarbourou, Laforgue, Montiel Ballesteros, E. Oribe, Pereda Valdés, Proust, Silva Valdés, J. Supervielle, Valéry.

Comentario: Revista literaria nacional de gran importancia. De interés para el comparatista para saber de las tendencias de la época.

LA PiUma. Montevideo. Revista mensual de ciencias, artes y letras. I, 1, agosto 1927-1931. (BNU, 19 tomos; UCLA).

Directores: C. Sabat Ercasty, A. Zum Felde.

Programa: "... afirmar... la existencia de una revista puramente intelectual, cuyas páginas, sean a la vez que un exponente amplio de la 
mentalidad nacional... un órgano que refleje el movimiento intelectual del mundo..."

Autores: J. de Ibarbourou, P. Morand, E. Oribe, C. Vaz Ferreira, Verhaeren, Whitman.

Comentario: Muy importante como índice de la cultura literaria nacional, e importante también para el comparatista. Considerada como uno de los más hermosos ejemplares de artes gráficas en el país.

ENSAYOS. Montevideo. Mensual. I, 1, julio 1936-21, agosto 1939. (UCLA).

Director: E. Petit Muñoz.

Autores: J. C. Abellá, Bécquer, N. Bohr, L. de Broglie, García Lorca, R. Ibáñez (sobre Bécquer), A. Llambías de Azevedo (sobre Neruda), E. Mallea, E. Oribe, H. Quiroga, Francisco Romero, I.. A. Sánchez, J. Supervielle, A. A. Vasseur, C. Vaz Ferreira, M. E. Vaz Ferreira.

Comentario: Excelente revista de ideas y de crítica literaria. El número 11 está dedicado a $\mathrm{H}$. Quiroga; el número 16 a García Lorca.

Revista Nacional. Montevideo. Literatura, arte, ciencia. Mensual. I, 1, enero 1938-. (UC; UCLA; UT).

Director honorario: R. Montero Bustamante.

Programa: "La Revista nacional se propone crear un repertorio de la cultura contemporánea e histórica del Uruguay."

Autores: J. G. Antuña, V. Carrera, J. J. Casal, José María Delgado, M. Falcão Espalter, N. Fusco Sansone, J. L. Gomensoro, P. L. Ipuche, J. Lerena Juanicó, J. Llambías de Azevedo, M. Medina Bustamante, V. Pérez Petit, C. Reyles, C. Sabat Ercasty, F. Silva Valdés, A. Storni, J. Zorrilla de San Martín, A. Zum Felde.

Comentario: Cito otros nombres de "autores" que no figuran en Carter. La revista se cambió a publicación trimestral al ser encomendada a la Academia Nacional de Letras por decreto del 7 de diciembre de 1955. J. Pereira Rodríguez es el nuevo director honorario, y el consejo consultivo consta de D. Castellanos, E. J. Couture, J. M. Delgado, A. D. González, y E. Oribe. Véase: Carter.

Mentor. Montevideo. Arte, literatura, crítica y bibliografía. Mensual.

Ilustrada. I, 1, agosto 1938-. (PAU).

Director: S. Cordero Criado. 
Boletín de la Academia Nacional de Letras. Montevideo, I, 1, julio 1946-IV, 15, diciembre 1954. (UCLA).

Comentario: Además de las conferencias, actas y otros datos sobre las actividades de la Academia, publica importantes trabajos sobre lengua y literatura. Sólo hubo 15 números.

Escritura. Montevideo. Ensayo, crítica, poesía, novela y cuento, música.

I, 1, octubre 1947-1948. (UCLA).

Comentario: Grabados e ilustraciones. Sólo hubo 9 números.

Margrnalia. Montevideo. Cuaderno de arte y literatura. Bimestral. I, 1, noviembre 1948-I, 6, diciembre 1949. (UCLA).

Director: M. Benedetti.

Propósito: "No queremos que Marginalia sea producto de un círculo $\mathrm{y}$ tan poco círculo somos que algunos de nosotros..., aún no nos hemos visto las caras."

Autores: M. A. Abella, H. H. Barbagelata, T. S. Eliot, M. Fingerit, E. M. Forster, Kafka.

Comentario: Hay homenaje a Goethe en el número 5. Sólo hubo 6 números.

Número. Montevideo. Bimestral. I, 1, marzo-abril 1949-IV, 27, diciembre 1955. (UC; UCLA).

Directores: M. Benedetti, M. A. Claps, E. Rodríguez Monegal, I. Vilariño.

Administrador: H. D'Elia.

Redactor responsable: E. Rodríguez Monegal.

Director gráfico: S. Cabrera.

Autores: E. Anderson Imbert, A. Barea (sobre García Lorca), J. L. Borges, R. Caillois, A. Camus, T. S. Eliot, J. Ferrater Mora, J. Guillén, H. James, K. Jaspers, J. R. Jiménez, Kafka, D. H. Lawrence, T. Mann, H. Miller, C. D. Molina, Neruda, C. Onetti, K. A. Porter, H. Quiroga, A. Reyes, Rodó, E. Rodríguez Monegal (sobre Azuela), M. Rojas, E. Sábato, P. Salinas (el número I8, I952, en homenaje al poeta), G. de Torre, C. Vaz Ferreira, T. Williams.

Comentario: Revista sólida e incitante en que se ven reflejados tanto los valores tradicionales como las tendencias de última hora. Desde el punto de vista de la erudición seria y ejemplar es, sin duda, una de las mejores revistas hispanoamericanas de nuestros tiempos. Gran interés en 
lo contemporáneo nacional y universal. Buenos estudios sobre lo mejor de la literatura nacional. Véase tan sólo el tomo dedicado a "La literatura uruguaya del 900," por A. Ardao y otros (II, números 6-8, 1950). Cada tomo lleva un índice general.

Revista Del Instituto Nacional de InVestigaciones y ARchivos LITERARIOS. Montevideo. I, 1, diciembre 1949.

Comentario: Publicóse sólo un número de 557 páginas, con láminas fuera de texto. Muy dignos de atención son los siguientes trabajos: L. Ayestarán, "La primitiva poesía gauchesca en el Uruguay (1812-1851)"; J. E. Etcheverry, "Un discurso de Rodó sobre el Brasil"; A. Llambías de Azevedo, "Los Anales del Ateneo del Uruguay"; E. Rodríguez Monegal, "El Diario de Viaje a París de Horacio Quiroga"; J. C. Pebet, "Nuevos aportes para la biografía de Juan Aurelio Casacuberta."

AsIR. Mercedes. Revista de literatura. 1950-1951.

Comentario: En ella colaboraron M. Benedetti y otros de la joven generación.

Clima. Montevideo. Cuadernos de arte. I, 1, julio 1950-diciembre 1950. (UCLA).

Director: R. Artagaveytia.

Autores: J. C. Âlvarez, A. Bazin, C. Drummond de Andrade, G. Greene, A. Somers, G. de Torre.

Comentario: Revista dedicada más a las artes plásticas que a la literatura, pero aún importante para el investigador literario por las relaciones así establecidas entre la literatura y las demás artes.

Mrro. Montevideo. Bimestral. 1951-1952. (UCLA).

Comentario: Sólo hubo dos números.

Azul. Montevideo. Revista literaria de América. Trimestral. 1953-1954.

(UCLA).

Directores: A. Esteban, J. Gonzalo, A. Vidal.

Propósito: ". . respetuosos de los valores vigentes de nuestro común pasado, Azul of récese liberalmente a la juventud del continente que comulgue en sus propósitos fundamentales. Más que engendrar una realidad inmediata y definida pretende esbozar una lúcida realidad futura. De ahí que su nombre trasunte también un anhelo de claridad y elevạciọn:" 
Autores: A. Capdevila, G. Díaz-Plaja (sobre Martí), H. Hatzfeld, L. Monguió (sobre M. Adán), Neruda, E. Oribe, M. E. Vaz Ferreira, A. Zum Felde.

Comentario: Consta de excelentes ensayos de crítica literaria. Publicáronse sólo dos números de 146 y 134 páginas respectivamente.

Las Entregas de la Licorne. Montevideo. 1953-1960.

Directora: S. Soca.

Comentario: Sólo hubo doce números.

VeletA. Paysandú. Revista de artes y letras. Trimestral. Julio 1955diciembre 1955.

Comentario: Publicáronse sólo dos números de 76 y 78 páginas respectivamente.

DesLiNDE. Montevideo. Literatura-artes. 1956-1960.

Director: B. Milla.

Comentario: En ella colaboraron M. Benedetti y otros de la juventud uruguaya. Sólo hubo 13 números.

\section{SUPLEMENTO}

No he podido precisar las fechas de publicación de las siguientes revistas:

Alfar. Montevideo. (BNU).

Comentario: Revista contemporánea en que han colaborado M. Benedetti y otros de su generación.

Apolo. Montevideo.

Director: M. Pérez y Curis.

Comentario: Revista del avancismo literario y social del elemento juvenil del período 1905-1915.

Los Nuevos. Montevideo.

Fundadores y directores: F. Morador, I. Pereda Valdés.

Comentario: Órgano de los creacionistas, ultraístas y demás vanguardistas de los 1920.

Las notas biobliográficas de las antologías suelen afirmar: "... ha colaborado con éxito en todas las tevistas literarias del país y en algunas del extranjero." Sin datos precisos, Montero Bustamante cita tales publi- 
caciones con excesiva generosidad al hablar de las actividades de los poetas de su Parnaso oriental. Menciono los títulos de algunos que pudieran ser de interés para el investigador literario: La alborada del Plata (p. 240), América literaria (p. 349), Eco de la juventud oriental (p. 82), El eco uruguayo (p. 83), Ecos americanos (p. 83), La floresta uruguaya (p. 240), La idea (p. 120), La ilustración del Plata (p. 83), La literatura del Plata (p. 83), La ondina del Plata (p. 240), El pensamiento (p. 83), El Plata ilustrado (p. 83), La revista (fundador $M$. Herrero y Espinosa; "periódico de literatura en que colaboró toda la juventud intelectual de la época", p. 152), Revista americana (p. 120), Revista cientifico-literaria (p. 120), La revista del Platt (p. 152), y Rojo y blanco (p. 219).

También cita a A. Magariños Cervantes como fundador de La revisia de ambos mundos de París allá por 1851-1855 (p. 61).

\section{VENEZUELA}

LA Guirnalda. Caracas. 1839.

Director: J. L. Ramos.

Véase: P. Grases, Indices analíticos (Caracas 1956).

Miscelánea Política y Literaria. Caracas. 1839-1840.

EL Repertorio. Caracas. Revista de ciencias, literatura y variedades. 1844.

Directores: C. Mendoza, T. Rojas.

El Álbum. Caracas. Periódico de literatura y artes. 1845.

Director: A. Lozano.

El Repertorio. Caracas. Periódico de ciencias, literatura, attes, industria, historia y variedades. Febrero-junio 1845.

La Aurora. Caracas. Periódico político y literario. 1846.

Comentatio: Es "distinto del de 1837".

El Album Literario y Musical. Caracas. 1854.

Directores: J. A. Egui, D. Santos Ramos.

El ARTista. Caracas. 1854.

Directores: A. Peoli, M. M. Poleo, 
El Ateneo. Caracas. Periódico quincenal de ciencias, literatura y artes. I, 1 mayo 1854-1855.

Editores: J. A. Calcaño, F. Soublette.

Comentario: Más tarde fue bautizada Brisas del Avila. "Se conserva la misma forma ..., y no el título, por ser éste puramente literario."

El Mosaico. Caracas. Mensual. 1854-1857.

Director: L. Delgado Correa.

Autores: R. M. Baralt, J. M. Cajigal, E. Calcaño, J. H. García de Quevedo, F. Toro.

El Museo Literario. Caracas. 1855-1856.

Director: G. E. Blanco.

El Foro. Caracas. Bisemanario. 1857-.

Directores: E. Escobar, L. Sanojo.

Comentario: En sus páginas se publicó, en 1857 (núms. 71-78), "una breve revista de los hombres más notables que en la literatura produjo. Venezuela desde los principios del siglo décimo noveno."

Gimnasio de Literatura. Caracas. 1859.

Director: G. E. Blanco.

LA CRónICA. Caracas. Revista literaria. 1864.

Directores: V. Coronado, M. M. Fernández.

El Museo Ilustrado. Caracas. 1864.

Directores: N. Bolet Peraza, R. Bolet Peraza.

LA Revista Literaria. Caracas. 1865-1866.

Director: J. V. González.

Véase: Edición facsimilar de la Revista literaria, por Juan Vicente González (Caracas 1956). La "Presentación" de Pedro Grases explica la edición y el valor de dicha publicación.

LA Revista. Caracas. Álbum de la familia. Semanario. 1872. Fundador: L. A. Aguilar.

El Ensayo Literario. Caracas. Semanario. I, 1, septiembre 1872-I, 51, septiembre 1873.

Alianza Literaria. Caracas. 1880.

Comențario: "Organo de la juventud caraqueña". Waxman, I8, 
El Popular. Caracas. Semanario de literatura y variedades. 1880-.

Fundador: J. Gil Fortoul.

Revista Venezolana. Caracas. 1881.

Fundador y director: José Martí.

Comentario: Salieron dos números correspondientes a 1 y 15 de julio.

Véase: J. Nucete Sardi, "Revista venezolana de José Marti", Cultura universitaria, 35-36 (1953), 79-82.

El Semanario. Maracaibo. 1881.

Director: J. Calcaño.

LA Entrega Literaria. Caracas. Revista semanal de literatura, ciencias $y$ artes. I, 1, 2 diciembre 1882-.

Fundador: E. Méndez y Mendoza.

Redactores: E. Blanco, J. Gutiérrez Coll, J. de D. Méndez y Mendoza, T. Michelena, J. M. Morales Marcano, G. Picón-Febres, F. Pimentel, D. Santos Ramos.

La LiRa Venezolana. Caracas. Repertorio de bellas artes y literatura. 1882-1886.

BRISAS DEL ORINOCO. 1888.

Fundador: C. de Taylhardat.

la América Ilustrada y Pintoresca. Caracas. Quincenal. I, 1, 1 octubre 1888-II, 32, 15 enero 1890. (BNV, 1 tomo).

Director-propietario: P. Martel Larruscaín.

Autores: A. Bello, Bocage, J. A. Calcaño, Gautier, J. Gil Fortoul, J. Gutiérrez Coll, Leconte de L'Isle-Adam, R. Litton, L. López Méndez, C. Matto de Turner, L. Pérez de Zambrana, R. Pombo, A. Rojas, M. Sánchez Pesquera, F. Soublette, Sully-Prudhomme, F. Toro.

Comentario: Llaman la atención los estudios de J. A. Calcaño sobre Bocage, de J. Gutiérrez Coll sobre Sully-Prudhomme, y de M. Sánchez Pesquera sobre $R$. Litton. Revista de intereses predominantemente nacionales, de limitado interés para el comparatista. A pesar del título no hay ilustraciones. Véase: S. Key-Ayala, "La América ilustrada y pintoresca", en Revista nacional de cultura, 82-83 (1950), 14-21.

El Zulia Ilustrado. Maracaibo. Mensual. I, 1, 24 octubre 1888-1891. (BNV, 1 tomo). 
Director: E. López Rivas.

Comentario: De escaso interés literario.

La Revista Universal Ilustrada. Caracas. 1891.

Fundador: C. Zumeta.

Directores: T. Aldrey Jiménez, A. J. Vegas.

Las Bellas ARtes. Valencia. Literatura y música. Quincenario. 1892.

Director: M. L. Rodríguez.

El Cojo Ilustrado. Caracas. Quincenario. 1892-1915. (LC; UT).

Comentario: Hay un índice, inédito, preparado por Joan Ciruti como parte de su tesis para el grado de M. A., Universidad de Oklahoma, 1954. Véase: Carter; Leavitt; y R. A. Rondón Mátquez, Itinerario de El cojo iiustrado, incursión a través de las páginas de "la mejor revista venezolana", Caracas, Tip. Gairedo, 1943, 154 pp.

Ciencias y Letras. Caracas. Organo de la sociedad Amantes del Saber. 1893.

Flores y Letras. Curazao. Órgano de la sociedad "Alegría" en Coro. 1893.

Boletín Lrterario. Carúpano. Semanario. 1894.

Director: M. T. Visso.

Miniaturas. Coro. Revista semanal de literatura. 1894-.

Director: F. Valderrama.

Cosmópolis. Caracas. Quincenal de letras y artes. I, 1, mayo 1894-II, 12 julio 1895.

Directores: P. E. Coll, P. C. Dominici, L. M. Urbaneja Achelpohl.

Véase: P. Grases, "En el cincuentenario de Cosmópolis", reproducido en P. Grases, Materiales para la bistoria del periodismo en Venezuela, 228-234. El original (Caracas 1944), de sesenta páginas, es una antología de los articulos doctrinales publicados en Cosmópolis, precedida de un estudio sobre la revista, su tiempo y sus colaboradores.

Revista Literaria de los Andes. Mérida. Mensual, I, 1, noviembre 1894-II, 23, septiembre 1896. (BNV, 1 tomo).

Director-propietario: G. Maldonado, h.

Redactores: E. C. Guerrero, A. Quintero Rojas, V. M. Ramírcz. Autores: I. Casola, Darío, G. Picón-Febres, 
Comentario: Las contribuciones son casi exclusivamente de los redactores mismos. De poco interés para el comparatista.

Horizontes. Ciudad Bolívar. Mensual. Órgano del Centro CientíficoLiterario de Ciudad Bolívar. 1900-.

Venezuela Ilustrada. Caracas. Quincenario de ciencias y letras. 1901-.

La Semana. Caracas. Revista científica, literaria, artística y amena. I, 1, 1 mayo 1901-V, 236, 24 febrero 1906. (BNV, 23 tomos).

Director: R. A. García.

Redactor: J. de D. Méndez, hijo.

Autores: J. Arolas, Banville, Olavo Bilac, E. Blanco, P. Bourget, Byron, J. Calcaño, Casal, Claretie, L. Coloma, Coppée, Darío, D’Annunzio, Daudet, J. D’Sola, Echegaray, P. Féval, A. France, I. Gamboa, F. Gavidia, R. Giovagnoli, E. Gómez Carrillo, J. V. González, Guerra Junqueiro, G. Gutiérrez González, Gutiérrez Nájera, Hugo, Lamartine, Lamennais, Lemaître, Leopardi, Longfellow, Martí, Mauclair, Maupassant C. Mendès, Montalvo, Nervo, A. Osuna, Pérez Bonalde, Pérez Galdós, Poe, E. Poirier, Ponson du Terrail, E. Raymond, F. Ribas, B. Rivadó, E. Rostand, Rouvier, S. Rueda, S. Rusiñol, Saint-Victor, M. Sánchez Pesquera, L. Sanojo, J. Sardá, Sienkiewicz, J. A. Silva, S. F. Smith, E. Souvestre, Stecchetti, F. Tejera, Tolstoi, F. Tosta García, Turguenev, Unamuno, Valera, J. Verdaguer, J. Verne, H. G. Wells, O. Wilde, Zola, Zschokke, C. Zumeta.

Comentario: De especial interés son las traducciones, que son numerosas: A. Osuna traduce "My Country" Tis of Thee", de S. F. Smith; E. Poirier, ¿Quo vadis? de Sienkiewicz; L. Sanojo traduce Historia de Julio César, de Lamartine; J. Sardá, El Nabab de Daudet; hay seis traducciones distintas del poema "The Rainy Day" de Longfellow. También llaman la atención: Venezuela beroica de E. Blanco; Blanca de Torrestella, novela inédita de J. Calcaño; La gorriona de L. Coloma; la biografía de J. V. González por J. F. Ribas; y Perfiles venezolanos de F. Tejera.

Revista importante tanto para las letras nacionales como para la literatura comparada.

ARTE. Maracaibo. Revista literaria mensual, I, 1, abril 1908-V, 39, septiembre 1912. (BNV, 1 tomo).

Director-redactor: J. A. López.

Autores: Casal, Díaz-Rodríguez, Maupassant, J. A. Silva, Ugarte, Urbina: 
Comentario: En una especie de presentación de la revista, titulada "Tributo fraternal", el Dr. E. C. Guerrero de Quito termina con estas palabras: "Sigue el joven López en pos de triunfos y conquistando aplausos, y lleva como lema las bellisimas palabras del poeta yankee:

$$
\begin{aligned}
& \text {... to act, that each tomorrow } \\
& \text { finds us further than today." }
\end{aligned}
$$

Revista antológica y de tendencia modernista, de escaso valor, tanto para las letras nacionales como para la literatura comparada.

AtEnas. Caracas. Revista quincenal de ciencias y artes. I, 1, 15 octubre 1908-1922. (BNV, 9 tomos).

Directores-propietarios: R. Arévalo González, E. de Arévalo González, A. Bernal, E. Porras Bello, C. Urdaneta H.

Propósito: " . . siempre será selecto y casi en su totalidad de producciones nacionales, especiales o inéditas..."

Autores: P. Adam, P. Altenberg, Banville, Baudelaire, Benavente, Blanco-Fombona, Blomberg, P. Bourget, Byron, D. Carbonell, E. Carrere, E. Castillo, E. de Castro, P. Claudel, Coleridge, P. E. Coll, L. Correa, J. J. Churión, Darío, D'Annunzio, L. Díaz, M. Díaz-Rodríguez, Diez-Canedo, Eça de Queiroz, P. Fort, A. Fouillée, A. France, R. Gallegos, A. Gide, Goethe, Gogol, Gómez Carrillo, E. G. González, Gorki, R. de Gourmont, Guerra Junqueiro, J. M. Guyau, K. Hansum, Heine, Herrera y Reissig, T. Hood, W. James, F. Jammes, J. R. Jiménez, S. Key-Ayala, Leopardi, Longfellow, Lord Lytton, J. Lorrain, Loti, Lugones, A. Machado, M. Machado, Maeterlinck, J. Maragall, Martí, Mauclair, C. Mendès, J. Michelet, G. Nerval, Nervo, Nietzsche, Condesa de Noailles, C. Obligado, Ortega y Gasset, R. Pérez de Ayala, Poe, A. de Quental, H. Regnier, Rimbaud, J. E. Rivera, Rodenbach, Rodó, R. Rolland, C. Rossetti, D. G. Rossetti, S. Rueda, S. Rusiñol, Ruskin, Samain, M. Sánchez Pesquera, J. Semprun, Shelley, F. Sicardi, J. A. Silva, R. I. Stevenson, A. Storni, Tagore, Tennyson, Tolstoi, F. Turcios, Turguenev, Uhland, Unamuno, L. M. Urbaneja Achelpohl, G. Valencia, Valle-Inclán, Verhaeren, Verlaine, Villaespesa, Wodsworth, Whitman, O. Wilde, W. B. Yeats, C. Zumeta.

Comentario: A pesar de lo anunciado en el propósito, se da más espacio a la literatura extranjera que a la nacional, como se ve fácilmente en la lista antológica de las firmas más célebres de casi todos los 
países del mundo. Refleja los gustos literarios de una época aún modernista. Interesa notar la importancia dada a Tagore, a los poetas románticos de Inglaterra, a Baudelaire, y a otros no siempre acogidos por otras revistas hispanoamericanas. Desde 1914 en adelante, se hace cada vez más internacional. Importante para los años postmodernistas y para el comparatista.

La Alborada. Caracas. 1909-1910.

Directores: R. Gallegos, J. Planchart, J. Rosales, E. Soublette.

Comentario: Importante revista ideológica del grupo reformista de la época. Véase el índice inédito, preparado por Joan Ciruti como parte de su tesis para el grado de M. A., Universidad de Oklahoma, 1944. Y véase también el trabajo de Lowell Dunham sobre "Rómulo Gallegos and the Generation of La albordda", Hispania, XXXIX (1956), 186-190.

La Guirnalda. Carora. Revista literaria quincenal. 1910.

Director: V. Crespo Meléndez.

Comentario: Quiso ser continuación de las anteriores $(1887,1894)$ del mismo nombre.

Alma Venezolana. Caracas. Mensual. I, 1, 1 marzo 1910-II, 28, 30 abril 1911. (BNV, 1 tomo).

Directores: A. Fernández García, L. M. Urbaneja-Achelpohl.

Autores: G. Arciniegas, Baudelaire, Benavente, Bolívar, D. Carbonell, E. Castillo, E. de Castro, P. E. Coll*, Darío, D'Annunzio, DíazRodríguez*, Eça de Queiroz, Emerson, A. France, Ganivet, M. González Prada, Gutiérrez Nájera, Heredia (francés), J. Ingenieros, J. R. Jiménez, S. Key-Ayala, Leconte de L'Isle Adam, Lemaître, Lugones, Maeterlinck, Mallarmé, L. Marroquín, Martí, Nietzsche*, C. Palma, Pardo Bazán, Pérez Bonalde, E. Ramírez Angel, S. Rueda, Rusiñol, Sanín Cano, J. Semprum, J. A. Silva, Swinburne, Thoreau, Tolstoi, C. A. Torres, G. Valencia, Villaespesa, $\mathrm{O}$. Wilde.

Comentario: Revista del tipo antológico, de tendencia modernista pero de una importante colaboración nacional de la cual no aparecen citados aquí sino unos cuantos nombres venezolanos. De interés para el comparatista.

SAGrtario. Caracas. Sale tres veces cada mes. I, 1, 3 abril 1911-I, 10, 1 julio 1911. (BNV, 1 tomo).

Director: J. Semprum. 
Autores: P. Adam, J. Calcaño, D. Carbonell, P. E. Coll, L. Churión R. de Gourmont, C. Hispano, W. James, S. Key-Ayala, L. Landaeta, Lugones, Nordeau, Poe, Sarmiento, O. Wilde, C. Zumeta.

Comentario: Revista setia y de importancia para las letras nacionales. De limitado interés para el comparatista.

VIDA NueVA. Caracas. 1912-1913. (BNV).

Comentario: De escaso intéres para el investigador literario.

Venezuela Contemporánea. Caracas. 1917-1918.

Directores: G. Espinosa, A. E. de la Rosa.

LeTRAS. Carúpano. 1917-1920.

Ciencia y ARTte. Carúpano. Revista literaria y científica. Semanario. 1918.

Arístides Rojas. Mérida. 1918-.

Fundador: M. Picón Salas.

Cultura Venezolana, Caracas. Mensual. 1918-1934. (HU; LC; NYU; UCLA).

Véase: Leavitt.

Billiken. Caracas. Revista ilustrada. Semanal. I, diciembre 1919-. (BNV, completa y corriente, y examinada hasta 1926).

Director: L. Manzano.

Autores: E. About, R. Angarita Arvelo, A. Arraiz, Azorín, Baudelaire, Olavo Bilac, N. Bolet Peraza, J. L. Borges, Byron, E. Castillo, P. E. Coll, Chocano, D'Annunzio, Darío, Díaz-Rodríguez, Eça de Queiroz, A. France, R. Gallegos, Gautier, R. Gómez Rincones, E. G. González, R. de Gourmont, F. Grandmontagne, Heredia, A, HernándezCatá, J. R. Jiménez, Kipling, Leconte de L'Isle Adam, Lugones, Lloréns Torres, Maeterlinck, V. Medina, G. Mistral, Nervo, Papini, T. de la Parra, U. Pérez, R. Pérez de Ayala, M. Picón-Salas, Poe, A. Rojas, Samain, J. A. Silva, A. Storni, Sully-Prudhomme, Swinburne, J. J. Tablada, Tagore***, L. M. Urbaneja Achelpol, A. Uslar Pietri, G. Valencia, Verlaine, Villaespesa, Whitman, $\mathrm{O}$. Wilde, Zamacois.

Comentario: Revista del tipo antológico, de variada representación literaria universal, de viejos valores reconocidos y de nombres que pronto han de ser los valores nuevos (A. Arraiz,1920; G. Mistral, 1920; Picón- 
Salas, 1920; Uslar Pietri, 1924). Llaman la atención el gran interés en Tagore, el espíritu whitmanesco de A. Arraiz en su "Oda a Henry Ford" ("él es la democracia"), marzo 1925, y lo de U. Pérez y de R. González Rincones sobre Baudelarie y Kipling respectivamente.

ArIEL. Maracaibo. Revista de literatura. Semanal. 1921-.

ARTE Y LABor. Caracas. 1923-.

Director: R. Benavides Ponce.

Élite. Caracas. Revista semanal ilustrada. I, 1, 17 septiembre 1925. 1932. (BNV, completa y corriente).

Editores-propietarios: Aguerrevere, Guruceaga y Cía.

Secretario: R. Carrasquel y Valverde.

Autores: R. Angarita Arvelo, Olavo Bilac, A. E. Blanco, C. O. Bunge, J. Claretie, M. Dounay, Eça de Queiroz, J. Fombona Pachano, A. France, J. Jiménez Rueda, Kipling, Lugones, G. Mistral, Nervo, M. Otero Silva, F. Pimentel, Pirandello, Poe, J. M. Salaverría, J. Schmidke, E. Serpa, J. A. Silva, P. Sotillo, J. Stephens, J. J. Tablada, Unamuno, L. M. Urbaneja Achelpohl, A. Uslar Pietri, Villaespesa, O. Wilde.

Comentario: Revista acogedora tanto de las grandes firmas internacionales como de las más nuevas nacionales. Sólo examiné hasta el año 1928.

LA QUINCENA LITERARIA. Barquisimeto. 1927-.

Nos-otras. Caracas. Bisemanario. 1927-1943.

Directores: A. M. Barroeta, L. Martínez.

Válvula. Caracas. 1928.

Comentario: Revista en que se recogieron los primeros ensayos de surrealismo.

El INgenioso Hidalgo. Caracas. 1930.

Comentario: Una de varias revistas en que, con marcado retraso, se presenta la literatura de vanguardia en el país.

IA GACETA de AmÉRICA. Caracas. 1934.

Comentario: Revista de vanguardia.

Cultura Nacional. Caracas. Revista literaria y científica. Mensual. 1935-1944. (BNV; UT').

Director: J. M. Núñez Ponte. 
Redactor administrador: J. A. García.

Véase: Carter.

Revista Nacional de Cultura. Caracas. Bimensual. 1938-. (TU;

UCLA; UN; UT).

Véase: Carter.

VIDE. Caracas. 1939-. (BNV).

Comentario: Revista universitaria de intereses generales y de literatura inédita, pero de escaso valor para el comparatista.

Viernes. Caracas. Poesía y crítica. I, 1, mayo 1939-II, 22, mayo 1941. (BNV, 2 tomos, incompleta).

Dirección: Órgano del "Grupo Viernes" integrado por: F. Cabrices, O. D’Sola, L. Fernández Alvarez, V. Gerbasi, J. R. Heredia, R. Olivares Figueroa, A. M. Queremel (1899-1939), P. Rojas Guardia, O. Rojas Jiménez, P. Venegas Filardo. Intégranse los siguientes desde el número 5 correspondiente a diciembre de 1939: R. Díaz Sánchez, P. Grases, A. Junyent, U. Leo, J. Padrón, M. F. Rugeles, P. Sotillo, A. Vallmitjana.

Secretario: V. Gerbasi (números 1-5); P. Venegas Filardo.

Liminar: "Viernes, es decir, víspera del reposo... es un grupo sin limitaciones ..., y es ... , una revista que expone poesía, y que se expone."

Autores: Además de los mismos socios del Grupo, Carducci, J. Ca. rrera Andrade, León Felipe, M. Fingerit, Hölderlin, C. Meléndez, M. Picón-Salas, R. M. Rilke, Unamuno.

Comentario: De intereses mayormente nacionales; mucha poesía original; reseñas de libros nacionales y extranjeros; de importancia para el período, pero de limitado interés en cuanto a influencias y tendencias extranjeras.

El grupo literario "Viernes" se fundó en 1936.

Letras. Caracas. Organo del Centro Cultural Venezuela. Mensual. I, I, febrero $1942-$. (BNV).

Director: L. Cortina.

Redactores: E. Azcárate L., G. Brunicardi, M. García, F. Salazar, A. J. Sucre.

Comentario: Ilustraciones. Música. Poesía. Notas biográficas.

Miniatura. Caracas. Semanario literario y de variedades. 1, 1, julio 1942-. (BNV).

Director: E. Lovera. 
Revista del Caribe. Caracas. Mensual. 1942-. (BNV).

Director: V. Gerbasi.

Cantera. Barquisimeto. Revista literaria quincenal. I, 1, febrero 1942 1943.

Directores: C. Graterol, A. Graterol.

Ideas Venezolanas. Caracas. Síntesis del pensamiento venezolano de todos los tiempos. Mensual. I, 1, julio 1942-1946. (BNV).

Directores: R. C. Arraiz, R. Díaz Sánchez, M. A. Villarroel.

JAGÜEY. Barcelona. Revista literaria ocasional. Mensual. I, 1, enero 1943-. (BNV).

Brtácora. Caracas. Mensual. I, 1, marzo 1943-1944. (BNV; UT).

Directores: M. Briceño-Iragorry, V. Gerbasi.

Autores: D. Casanovas, T. Corbière, E. Dickinson, E. R. Embree, Giraudoux, I. Golla, P. Grases, J. R. Jiménez, Kipling, Conde de Lautreamont, J. Liscano, Mallarmé, J. Nucete-Sardi, E. Planchart, Poe, A. Rojas, D. G. Rossetti, E. St. Vincent Millay, Santayana, P. de la Tour du Pin, A. Uslar Pietri, Valéry Larbaud, Verhaeren, Whitman.

Comentario: Revista de gran promesa pero de corta vida por haber sido víctima de la Segunda Guerra Mundial. Importante para el comparatista.

Revista del Instituto Pedagógico Nacional. Caracas. Trimestral. I, 1, enero 1944-. (BNV, completa y corriente en 1947).

Director: O. Camacho.

Redactor: P. Grases.

Comentario: Cada número contiene por lo menos un artículo sobre lenguaje, literatura, folklore. Dedicada casi exclusivamente a las letras nacionales. De interés son los títulos sobre Teresa de la Parra, los romances españoles en Venezuela, la poesía contemporánea, Cosmópolis.

LETRAS. Caracas. La revista de la juventud venezolana. I, 1, marzo 1946-. (BNV).

Director: L. Cortina.

Travesía. Boconó. Literario-cultural. Mensual. I, 1, 30 marzo 1946I, 5, 30 julio 1946. (BNV).

Director: O. Sambrano Urdaneta. 
Cultura Universitaria. Caracas. 1947-. (UCLA; UN; UT).

Comentario: Hay índice para los años 1947-1952. Véase: Carter.

Contrapunto. Caracas. Revista de letras y arte. I, 1, marzo 1948-. (BNV).

Directores: H. Mújiça, R. Pineda.

SARdio. Caracas. 1961-.

Fundador: A. González León.

Comentario: "Fundador de la revista Sardio que ha logrado crear un destacado grupo literario e impulsar con notable éxito las letras venezolanas."

\section{SUPLEMENTO}

Entre tantos venezolanos que contribuyeron a la prensa literaria de lengua española en el extranjero, cabe recordar aquí a dos del siglo pasado que se distinguieron por sus actividades en dos grandes centros del mundo inglés: A. Bello, en Londres, fundador, con el colombiano J. García del Río, de las célebres revistas Biblioteca americana (1823) y Repertorio americano (1826-1827)-véase: P. Grases, Tres empresas periodísticas de Andrés Bello. Bibliografía de la Biblioteca americana y el Repertorio americano, Caracas, Ministerio de Educación, 1955; y N. Bolet Peraza, en Nueva York, director de Las tres Américas y La revista ilustrada, revistas en que el venezolano recogió la obra de los proscritos hispanoamericanos de fines del siglo. Hasta Darío figuró entre los colaboradores.

Venezuela cuenta con excelentes trabajos sobre el periodismo y la imprenta nacionales. El más útil y el más importante de todos es la compilación, con prólogo y notas de P. Grases, titulado Materiales para la bistoria del periodismo en Venezuela durante el siglo $x i x$, Caracas, Universidad Ceñtral, 1950. Consta de 36 trabajos, generales y monográficos, entre los cuales se encuentran los estudios de E. G. González, Informe sobre el periodismo en Venezuela, J. E. Machado, Lista de algunos periódicos que vieron la luz en Caracas de 1808 a 1900, y J. López de Sagredo y Brú, Indice de periódicos y periodistas del Estado Zulia (18211948). El "Índice de títulos" recoge los nombres de más de 800 publicaciones periódicas. Un laborioso examen de todos los datos esparcidos por el tomo me decidió a citar aquí otros títulos, todavía no incluidos en este estudio, que pudieran ser de interés para el investigador literario. 
Sólo doy los nombres, salvo en el caso de los idénticos cuando ofrezca algún otro dato esclarecedor:

El album (1880); Album de las bijas del lago; Alfa; Alma y musa; Alondras; La atmósfera; Baudelaire; Bobemias; Canto y labor; El cisne del lago; El eco de la juventud (1877); Ensayos; El escolástico; La esperanza (1858); La esperanza (1875); Las flores de Pascua; La fraiernidad literaria; Gaceta literaria; La guirnalda (1887); La guirnalda (1894); La boja literaria; El iris (Puerto Cabello); El iris (Maracaibo); Letras (1898); Letras (1929); Letras patrias; Letras y numeros; La lira de occidente; El lirio (1872); La mañana (1868); La mariposa; Miniaturas (1899); La miscelánea (1905); Las nieblas; El pensamiento (1912); El pensil (1874); Le petit Fígaro; El pincel (1894); Psiquis; El rayo de luz (1884); El rayo de luz (1897); La revista literaria (1931); Revista literaria del Zulia; Säbado literario; Semana literaria; Senda lirica; Tierra firme; Vendimia; El vergel; Vida literaria; Violetas; La voz del porvenir.

Véase: J. Díez, "Periódicos literarios de Coro", Revista nacional de cultura, 120 (1957), 116-120; P. Grases, Indices analíticos (Caracas 1956) de las revistas: El liceo venezolano, La guirnalda, La oliva, Revista literarid y Vargasid; S. M. Waxman, "Venezuelan Periodicals" (18-23), A Bibliography of the Belles-Lettres of Venezuela, Cambridge, Harvard University Press, 1935; y el Anuario bibliográfico venezolano, Caracas, Tipografía Americana, 1944-1950. El Anuario cubre los años 1942-1948. Cada número lleva una sección sobre "Publicaciones periódicas venezolanas", de 25 a 50 páginas, repleta de datos inclusive el de la colocación de todas aquéllas consultadas en la BNV.

\section{INDICE BIBLIOGRAFICO}

(Ampliaciones y adiciones a la bibliografía de Carter)

Album del cincuentenario de la Asociación de Reporters de La Habana: 1902-1952. Habana, Edit. Lex, 1952, 440 pp.

Alisky, M. Latin American Journalism Bibliography. México, Fondo de Publicidad Interamericana, 1958, $59 \mathrm{pp}$.

Amiama, M. A. El periodismo en la Repuiblica Dominicana. Santo Domingo, "La nación", 1933, 95 pp. 
Anuario bibliográfico. La Plata, 1926-. (UCLA).

Anuario bibliográfico costarricense. San José, 1956-. Sustituye al Boletin bibliográfico, publicado por la Biblioteca Nacional.

Anuario bibliográfico puertorriqueño. Indice alfabético de libros, folletos, revistas y periódicos publicados en Puerto Rico. Río Piedras, Biblioteca de la Universidad, 1948-1955. (UCLA).

Anuario bibliográfico de la Repriblica Argentina. Buenos Aires, 18801888. Fundador: A. Navarro Viola. (UCLA).

Anuario prensa argentina y latino-americana. Buenos Aires, República Argentina Ediciones, 1939-1942, 1946, 1955. (UCLA).

Anuario de publicaciones periódicas cbilenas. Santiago, Biblioteca Nacional, 1930, 1952-1956.

Antologia ecuatoriana. Quito, Imp. de la Universidad Central, 1892, IV$685 \mathrm{pp}$.

Arias, A. Panorama de la literatura ecuatoriana. 2 ed. Quito, Imp. de la Universidad, $1948,470 \mathrm{pp}$.

Arias, A. El periodismo ecuatoriano. Quito, Imp. de la Universidad Central, 1938, 28 pp.

Arboleda, G. Apuntes sobre la imprenta y el periodismo en Popaján, 1813-1899. (Fotocopia imperfecta, UCLA).

Arrieta, R. A., editor. Historia de la literatura argentina. Buenos Aires, Peuser, 1959, 5 tomos.

Beltrán, O. R. Hisaria del periodismo argentino, pensamiento y obra de los forjadores de la patria. Buenos Aires, Sopena, 1943.

Boletín bibliográfico argentino. Buenos Aires, 1937-1946. (UCLA).

Catálogo ... Biblioteca de D. Antonio Santamarina. Buenos Aires, 1955. Contiene una lista de más de 1000 revistas de todas partes, pero principalmente de los paises rioplatenses, de las cuales muchas son literarias.

Catálogo del Fondo José Maria Quijano Otero. Bogotá, "El gráfico", $1935,318 \mathrm{pp}$.

Catálogo de todos los periódicos que existen en la Biblioteca Nacional desde su fundación hasta el año de 1935, inclusive. Bogotá, "El gráfico", 1936, 2 tomos.

Destruge, C. Historia de la prensa de Guayqquil. Quito, Tip. y Encuad. Salesianas, 1924-1925, 2 tomos.

Diccionario de la literatura latinoamericana: Argentina. Washington, Unión Panamericana, 1960-1961, 2 tomos: 
Diccionario de la literatura latinoamericana: Bolivia. Washington, Unión Panamericana, s.f. (1958), IX-121 pp.

Diccionario de la literatura latinoamericand: Chile. Washington, Unión Panamericana, 1958, X-234 pp.

Diccionario de la literatura latinodmericana: Colombia. Washington, Unión Panamericana, 1959, X-179 pp.

Directory of Current Latin American Periodicals. Paris, UNESCO, 1958, XXV-226 pp.

Dobles Segreda, L. Indice bibliográfico de Costa Rica. San José, 1927-.

Durón, R. E. Honduras literaria. Tegucigalpa, Ministerio de Educación Pública, 1957-1958, 2 tomos.

Estrada, D. Historia y bibliografía de la imprenta en Montevideo (18101865). Montevideo, José M. Serrano, editor, 1912, 318 pp.

Faraone, R. La prensa de Montevideo. Montevideo, 1960.

Febres Cordero G., J. Tres siglos de imprenta y cultura venezolanas. $1.500-$ 1800. Caracas, Universidad Central, 1959, 223 pp.

Feliú Cruz, G. Colección de antiguos periódicos chilenos. Santiago, Biblioteca Nacional, 1952-. Desde el año 1814 al año 1822.

Finot, E. Historia de la literatura boliviana. 2 ed. La Paz, Gisbert, 1955, XXIII-651 pp.

González de Cossío, F. La imprenta en México (1553-1820). México, Universidad Nacional, 1952.

Labraña, J. M. Cuba en la mano. Habana, Ucar, García, 1940, pp. 649786, para un estudio de "La prensa en Cuba".

Láinez, N. La imprenta y el periodismo en la época colonial. Buenos Aires, 1924, $106 \mathrm{pp}$.

$A$ List of Literary and Cultural Magazines Received in the Columbus Memorial Library of the Pan American Union. Washington, Pan American Union, 1940, Bibliographic Series: 22.

Lista de las publicaciones periódicas cbilends. Santiago, Biblioteca Nacional, 1929. Revistas, diarios y periódicos recibidos por la Biblioteca Nacional entre 1915 y 1928.

Llaverias, J. Contribución a la bistoria de la prensa periódica. Habana, Atchivo Nacional, 1957-1960, 2 tomos.

Llaverías y Martínez, J. Los periódicos de Martí. Habana, Imp. Pérez, Sierra y Cía., 1929, 131 pp.

Medina, J. T. Bibliografía de la imprenta en Santiago de Chile desde sus 
origenes hasta febrero de 1817; adiciones y ampliaciones. Santiago, Universidad de Chile, 1939, XIV-140 pp.

Medina, J. T. Bibliografía de la imprenta en Santiago de Chile desde sus origenes hasta febrero de 1817; adiciones y ampliaciones. Obra póstuma. Santiago, Prensas de la Universidad, 1939, 140 pp.

Medina, J. T. La imprenta en Bogolá (1739-1821). Santiago de Chile, Imp. Elzeviriana, 1904, XXIII-101 pp.

Medina, J. T. La imprenta en La Habana (1707-1810). Santiago de Chile, Imp. Elzeviriana, 1904, XXXII-199 pp.

Medina, J. T. La imprenta en Lima (1584-1824). Santiago [author], 1904-1907, 4 tomos.

Medina, J. T. Historia y bibliografía de la imprenta en el antiguo virreinato del Río de la Plata. Buenos Aires, F. Lajouane, 1892, 2 tomos.

Menéndez, C. R. La evolución de la prensa en la peninsula de Yucatán (Yucatán y Campeche) a través de los uiltimos cien años. Mérida, Cía. Tipo. Yucateca, 1931.

Miró, Rodrigo. Cien años de poesía en Panamá (1852-1952). Panamá, Ministerio de Educación, 1953, XX-351 pp.

Montero Bustamante, R. El parnaso oriental. Montevideo [Maucci], 1905, $326 \mathrm{pp}$.

Montt, L. Bibliografía chilena. Santiago, Imp. Universitaria, 1904-1921, 3 tomos.

Ortega, J. J. Historia de la literatura colombiana. 2 ed. Bogotá, Cromos, $1935,1214 \mathrm{pp}$.

Ospina, J. Diccionario biográfico y bibliográfico de Colombid. Bogotá, Cromos, 1927-1939, 3 tomos.

Peraza y Sarausa, F. Bibliografías cubanas. Washington, Library of Congress, 1945, XIV-58 pp.

Pérez Ortiz, R. Anuario bibliográfico colombiano, 1951-1956. Bogotá, Instituto Caro y Cuervo, 1958, XX-334 pp.

El periodismo en Cuba. La Habana, "Libro Conmemorativo del Día del Periodista", 1953, 197. pp.

Posada, E. Bibliografía bogotana. Bogotá, Imp. Nacional, 1917-1925, 2 tomos.

Publicaciones periódicas cbilenas, anuarios de 1937 y 1938, Santiago, Universo, 1939, $45 \mathrm{pp}$.

Remos, J. J. Micrófono. Habana, Molina y Cía., 1937, pp. 221-227, 
para un estudio de "Las revistas cubanas más representativas deI siglo Xrx".

Remos y Rubio, J. Historia de la literatura cubana. Habana, Cárdenas y Cía., 1945, 3 tomos.

Rolando L., C. Crónica del periodismo en el Ecuador. 1792-1849. Guayaquil, 1947 , tomo I.

Romero Castillo, A. La imprenta de Guayaquil independiente (18211822). Guayaquil, 1956.

Rosa-Nieves, C. La poesía en Puerto Rico. 2 ed. San Juan, Edit. Campos, 1958, $301 \mathrm{pp}$.

Selva, M., Mendilaharzu, F., Rosso, L. J. Bibliografía general argentina. Inventario analítico-crítico de todas las publicaciones argentinas desde el origen de la primera imprenta en el Río de la Plata, hasta el presente. Buenos Aires, L. J. Rosso, 1931, 2 tomos.

Trelles y Govín, C. M. Bibliografía cubana de los siglos xvir y xvin. 2 ed. Habana, Imp. del Ejército, 1927, XIX-463 pp.

Trelles y Govín, C. M. Bibliografía cubana del siglo xix. Matanzas, Quiros y Estrada, 1911-1915, 8 tomos. El segundo tomo (1826-1840) contiene una "Relación de periódicos publicados en Cuba en el siglo $\mathrm{xx}$ ", firmada por F. Llaca.

Trelles y Govín, C. M. Bibliografia cubana del siglo xx (1900-1916). Matanzas, Quiros y Estrada, 1916-1917, 2 tomos.

Vaïsse, E. Bibliografía general de Cbile. Santiago, Imp. Universitaria, 1915.

Westruge, C. Historia de la prensa de Guaydquil. Quito, Tip. y Encuad. Salesianas, 1924-1925, 2 tomos.

Zimmerman, I. A Guide to Current Latin American Periodicals. Humanities and Social Sciences. Gainesville, Kallman Publishing Company, 1961.

Zuviría, F. La prensa periódica. Montevideo, Imp. de la República, 1857, $173 \mathrm{pp}$.

University of California

JOHN E. ENGLEKIRK

Los Angeles. 
